\title{
1 Geschichte der Heimat als Geschichte des langen 19. Jahrhunderts
}

Die Geschichte der Heimat ist eine Geschichte des langen 19. Jahrhunderts. ${ }^{1}$ In diesem Zeitraum wird Heimat eine neue semantische Dichte verliehen, die alle gesellschaftlichen Bereiche erfasst, und stiftet der Begriff jene begrifflichen Allianzen, die heute noch seinen Bedeutungshof eingrenzen. Der deutschsprachige Kulturraum entwickelt in dieser Zeit, zumindest in der Selbstwahrnehmung, ein besonders inniges Verhältnis zur Heimat: Heimatliebe galt im 19. Jahrhundert als spezifisch deutsch. Im 19. Jahrhundert verbindet sich die ältere, religiöse Bedeutung von Heimat auch mit irdischen Orten, die gleichwohl ins Licht der Unerreichbarkeit getaucht bleiben. Im Wort Heimat konstituiert sich ein bürgerliches Selbstverständnis, zu dem es gehört, bestimmte Bevölkerungsgruppen auszuschließen: die Armen und die Juden, aber auch den kosmopolitischen Adel. Bis heute arbeiten wir uns, meistens unbewusst, an diesem Heimatverständnis ab.

Auch wenn es das Wort Heimat schon länger gibt, beginnt die Geschichte des modernen Begriffs von Heimat in den drei Jahrzehnten vor 1800, um dann ab 1800 jene Wirksamkeit zu erlangen, die in unterschiedlichen Varianten bis heute anhält. ${ }^{2}$ Die neue semantische Dichte von Heimat entsteht durch die Transformation alter in neue Bedeutungen und deren semantische Schichtung: Dass Heimat zugleich erinnerter Kindheitsort und Ausdruck einer „ferneren und tieferen Heimat, von welcher jene nur ein lieblicher Widerschein zu sein scheint" sein kann, ist neu. ${ }^{3}$ Dass Heimat zugleich konkreter und transzendenter Ort ist, zugleich individuellen und religiösen oder auch mythologischen Ursprung bezeichnet, dass Heimat ein gefühlsbetontes, emphatisches Konzept wird und auch dass Heimat in ein komplexes, teils antagonistisches Verhältnis zum zeitgleich sich wandelnden Begriff des Vaterlandes bzw. der Nation tritt und damit den vermeintlich apoliti-

1 Eric Hobsbawm verwendet 1987 den Begriff des langen 19. Jahrhunderts in The Age of Empire. 1875-1914, dem letzten seiner drei, postum als Trilogie unter dem Titel Das lange 19. Jahrhundert erschienenen Bände. Dabei diskutiert er zwei verschiedene Jahreszahlen als Epochenzäsur: 1776, den Beginn der Amerikanischen, und 1789, den Beginn der Französischen Revolution, als Anfang, 1914 als Ende; vgl. Hobsbawm 2017, S. 18. Der Begriff ist inzwischen fest in der deutschen Geschichtswissenschaft eingeführt, meist mit dem Beginn 1789, vgl. Kocka 2001, Bauer 2010. Wird hier im Folgenden verkürzt vom langen 19. Jahrhundert gesprochen, ist dieser Epochenzusammenhang gemeint, wobei sich in Bezug auf Heimat der frühere Beginn Mitte der 1770er Jahre anbietet.

$2 \mathrm{Zu}$ einigen Grundthesen meiner Arbeit vgl. Oesterhelt: Topographien des Imaginären, 2016. 3 So der Protagonist Friedrich in Joseph von Eichendorffs Ahnung und Gegenwart (1815); Eichendorff 2007, S. 100.

Ә OpenAccess. () 2021 Anja Oesterhelt, publiziert von De Gruyter. (cc))BY-ND Dieses Werk ist lizenziert unter der Creative Commons Attribution-NonCommercial-NoDerivatives 4.0 Lizenz.

https://doi.org/10.1515/9783110707847-002 
schen Part innerhalb eines tatsächlich hochpolitischen Begriffsgefüges übernimmt, sind neue semantische Entwicklungen der sogenannten Sattelzeit. ${ }^{4}$

\subsection{Zu den Anfängen der Geschichte von Heimat}

Natürlich gab es schon weitaus früher Bedeutungen und Praktiken, die sich mit dem Wort Heimat verbanden. ${ }^{5}$ Wenn man nicht das Wort, sondern seine (dann jeweils zu bestimmende) Bedeutung sucht, so gehen die Auffassungen auseinander, was man historisch voraussetzen darf - die meisten gehen davon aus, dass es etwa das menschliche Bedürfnis nach einem emotional besetzten Lebensraum, nach raumbezogenen Identitäten immer schon gegeben haben dürfte. Sicher ist, dass das Wort Heimat dafür aber eher selten verwendet wurde. ${ }^{6}$

In einem definierten Textkorpus lässt sich das Wort Heimat systematisch suchen, und hier können für den Verwendungskontext und die Bedeutung des Wortes Heimat recht eindeutige Aussagen getroffen werden. Im Korpus des Deutschen Textarchivs (Abb. 15 und 16), der besten gattungsübergreifenden Textzusammenstellung für eine ergebnisoffene Untersuchung, ${ }^{7}$ kann bis zu den 1770er Jahren Folgendes festgestellt werden: Vom chronologisch ersten Treffer von 1603 an stammen mehr als die Hälfte der Funde aus geistlichen Texten (Erbauungsliteratur, Predigten, Leichenpredigten), alles andere ist eine breite Mischung

\footnotetext{
4 Reinhart Kosellecks Bestimmung des Zeitraums von ca. 1750 bis ca. 1850, innerhalb dessen sich die Begriffe gebildet haben, die die Moderne mit Bedeutung aufgeladen hat, bewährt sich auch hier.

5 Das althochdeutsche „heimôti“ wandelte sich im Mittelhochdeutschen zu „heimôte“, „heimuote“, „heimôt“ oder auch „heimuot“, vgl. Benecke 1990, S. 655. Viele Beiträge zu Heimat beginnen mit einer ausführlichen etymologischen Herleitung, vgl. exemplarisch Bastian 1995, S. 20-23. Zur Kritik an etymologisch fundierten Heimatdefinitionen vgl. Korfkamp 2006, S. 21. 6 Zu frühneuzeitlichen Heimatkonzepten vgl. Piltz 2007; Gotthard 2003; beide diagnostizieren, „dass die Vormoderne sehr wohl ein Verständnis von Heimat hatte, den Quellen aber der Begriff selbst nicht selbstverständlich ist“. Piltz 2007, S. 57. Piltz weist u. a. darauf hin, dass ein anderer Eindruck sich teils dadurch ergibt, dass in Übersetzungen der lateinischen Quellen oft das Wort ,Heimat' gewählt wird und diese modernen Übersetzungen daher bereits eine Deutung der Texte darstellen. $\mathrm{Zu}$ diesem durchaus folgenreichen Problem vgl. das Kapitel dieser Studie zum Odysseus-Mythos (II.1.3.1).

7 Die Sammlung des Deutschen Textarchivs DTA umfasst Belletristik, Gebrauchsliteratur und wissenschaftliche Literatur aus dem Zeitraum von ca. 1600 bis 1900. Im September 2021 umfassten die Datenbestände 4443 Werke. Das DTA, das ob seiner disziplinen- und gattungsübergreifenden Ausgewogenheit und Repräsentativität der Textauswahl beste digitalisierte Referenzkorpus für deutschsprachige Texte, verzeichnet 7079 Treffer für die Suchanfrage ,Heimat‘. Zur Bewertung dieser Quelle vgl. die folgenden Ausführungen.
} 
aus kriminalistischen, geographischen, volkspädagogischen, juristischen, medizinischen, naturgeschichtlichen Textsorten, Lebensbeschreibungen oder kaufmännischen Ratgebern und, quantitativ ebenso unauffällig wie die anderen Textsorten, auch einigem Literarischen. Diese beiden Bereiche - geistliche Texte hier, säkulare dort - prägen die Semantik der Heimat in besonderer Weise. In ihrer geistlichen Bedeutung transzendiert Heimat unser irdisches Leben. Die wahre Heimat ist in diesem eschatologischen, die Lehre von der vollendeten Welt betreffenden Sinn nie auf Erden zu finden. Die wahre Heimat ist bei Gott, und Leben auf Erden ist eine Vorbereitung darauf: „Wie solte Sie nicht zum Vater nach der Heimet verlangen?“8, heißt es 1673 in einer Begräbnisrede. Von dieser über Jahrhunderte sehr stabilen religiösen Begriffssemantik wird noch ausführlich die Rede sein (vgl. II.1.1).

Der christlichen Metapher einer himmlischen Heimat muss ein ,irdisches“ Modell von Heimat zugrunde liegen. Zieht man die säkularen Textzeugnisse heran, ist in der Regel immer der Herkunfts-, Geburts- oder Lebensort gemeint. Dabei wird der Begriff neutral verwendet. Er ist unspezifischer und weiter gefasst als die zeitgenössische rechtlich-administrative Bedeutung von Heimat (vgl. II.2.1), es ergibt sich aber auch keine Reibung zwischen der allgemeinen Bedeutung von Heimat als Ort der Herkunft und der juristischen, die sich auf die Zuständigkeit der Gemeinden für ihre Landeskinder bezieht. Die Zuschreibung einer Heimat dient in alltagspragmatischen Zusammenhängen einer administrativen Identifikation, wie sie im Todes- oder im Krankheitsfall notwendig werden konnte. Das Corpus juris von 1703 etwa sieht vor, dass jeder nicht identifizierbare Tote so lange öffentlich aufbewahrt werden sollte, „biß etwas gewisses von seinem Nahmen und Heymath“ ermittelt worden sei, zu welchem Zweck andernfalls „der Leib wieder ausgegraben“9 werden müsse. Im Umgang mit der Pest empfiehlt ein Pest-Büchlein aus dem Jahr 1714, den „Namen / Profession, Heimat / Alter / auch dessen Eltern Namen / und wo er vorher sich bey einem Herrn auffgehalten / treulich in ein gewiß Buch“ aufzuschreiben, damit man im Todesfall „alsdann gute Nachricht“ davon erhalten könne. ${ }^{10}$ Bei Grimmelshausen geht es 1670 um einen Ehevertrag, nach dem die Frau „1000 Reichsthaler Pargelt zubringen“ muss, der Mann sie dafür „in Teutschland zu seinem Heimath um dieselbige“ Summe für den Fall seines Todes ,versichern solte“. ${ }^{11}$

Oft werden in den Textzeugnissen des 17. und 18. Jahrhunderts Heimat und Vaterland noch mehr oder weniger synonym gebraucht (vgl. I.2.1). In der Ge-

8 Burckhard 1673, o.S.

9 Beide Zitate Geise 1703, S. 596.

10 Beide Zitate Bräuner 1714, S. 140.

11 Alle Zitate Grimmelshausen 1670, S. 100. 
schichte eines Diebes von 1627 bemerkt der Dieb „zum Wirth / es sey jhm ein Kleid auß seiner Heymat vnnd Vatterlandt geschicket worden“. ${ }^{12}$ Ein Kaufmannslexikon von 1756 rät, bei der Auswahl der Lehrjungen nicht nur auf Alter, gesundheitliche Konstitution, ökonomische Verhältnisse und Bildung, sondern auch auf die Herkunft zu achten, weil deren „Heimath, oder Vaterland“13 Rückschlüsse auf eine Eignung zum Kaufmannsberuf zulasse. Im Gegensatz zur Heimat meint Vaterland hier lediglich die größere administrative oder territoriale Einheit, kann aber wie die Heimat auch nur den Geburtsort bezeichnen. Im Zitat aus dem Kaufmannslexikon fällt beides möglicherweise auch deshalb zusammen, weil eine Handelsstadt zeitgenössisch zugleich die kleinste und größte Einheit sein kann, also zugleich konkreter Lebensort und autonomer Staat.

Immer bezeichnet die Heimat recht nüchtern die Herkunftsregion von Anklamern ${ }^{14}$ und Peruanern ${ }^{15}$ ebenso wie von Pflanzen ${ }^{16}$ oder Tieren. ${ }^{17}$ Von Johann Gottfried Schnabe ${ }^{18}$ bis zu Johann Karl Weze ${ }^{19}{ }^{19}$ ehmen auch Romanfiguren hin und wieder das Wort Heimat in den Mund. Aber auch hier heißt Heimat nicht mehr und nicht weniger als Ort der Herkunft, wobei meist offenbleibt, ob dies eher im geographischen oder sozialen Sinn, also als Ort, an dem die Familie oder die Nächsten wohnen, gemeint ist. Eine besondere Emphase, Doppeldeutigkeit oder Metaphorizität des Wortes fällt nicht auf.

12 Calvi 1627, S. 136.

13 Ludovici 1756, S. 260.

14 „So ist nun Ancklamb oder Anckelheim der Ancken oder Enckel heimath / da die alten Angli, die sich hernach in Engern / vnd weiter in Engelland / auff gemachet haben / zu Hause gehören.“ Micraelius 1639, o.S.

15 „Aber in der Hauptzierde ist ein grosser vnterscheid zwischen jhnen / Sintemal einer sein Haar mit Haarschnüren von dieser / ein anderer von einer andern Farben auffgebunden trägt / nach dem es in seiner Heymat der Brauch ist.“ Gottfried 1631, S. 113.

16 „Die Stauden selbst aus ihrer Heimath an andre Orte zu verführen, würde nicht gelingen, denn während dem Transport durch das heiße Jndianische Meer werden sie völlig ausgezehrt, und bleiben allenfals in einem so schwachen Zustande zwischen Tod und Leben, daß von ihnen keine Nachkommenschaft zu erwarten steht.“ Kaempfer 1779, S. 446.

17 „Er ist oft mit der Hyäne vermengt worden, und die schwankenden Berichte der Reisenden machens wahrscheinlich, daß man selbst in seiner Heimath andre Thiere mit ihm verwechselt.“ Blumenbach 1779, S. 105.

18 Bei Johann Gottfried Schnabel fahren die Seefahrer „nach unsrer Heymath zu“ und „gelangeten auch glücklich daselbst an“. Schnabel 1743, S. 408.

19 Johann Karl Wezels Romanprotagonist Belphegor klagt: „Wenn mich nur der unglückliche Sturm nicht so weit von meiner Heimath verschlagen hätte!“ Wezel 1776, S. 134. 


\subsection{Heimat im langen 19. Jahrhundert}

In den späten 1770er und dann den 1780er Jahren mischt sich ein neuer empfindsamer Ton in den Gebrauch des Wortes Heimat, und zwar in der Literatur: Im Umfeld des Göttinger Hainbundes entwickelt sich in der dem Dichterbund eigenen - und zeitgenössisch ausgesprochen polarisierenden - Mischung aus Sentimentalität, Pathos und Vaterlandsliebe auch eine neue politisch-ästhetische Semantik von Heimat. Während das Vaterland bis dahin wahlweise den Geburtsort, einen von vielen deutschen Kleinstaaten oder ein größer gedachtes Deutschland bedeuten konnte, wird das Vaterland nun nur noch in der letzten Bedeutung verwendet. In dem Maß, in dem das Vaterland für die größere utopische Nationalidee steht, bildet sich Heimat in der Literatur als komplementärer Begriff aus (vgl. I.2.1). Dem aggressiv-kämpferisch codierten gesamtdeutschen Vaterland steht nun eine gefühlvoll-passiv codierte Heimat als individueller Ort der Herkunft gegenüber. Innerhalb dieses Transformationsprozesses läuft noch längere Zeit die alte, nüchterne Bedeutung mit. Der von den Hainbündlern gehasste Zeitgenosse Wieland lässt Agathon sich auch weit von seiner „Heymath“20 entfernen - aber das nötigt Agathon keine Träne ab. Die Umbruchszeit um 1800 zeichnet sich durch das Nebeneinander alter und neuer Heimatbegriffe aus: Charakterisiert Kant den Deutschen als „Kosmopolit[en]“, der „keinen Nationalstolz“ habe und „auch nicht an seiner Heimat“ hänge, ${ }^{21}$ gleicht der Deutsche bei Hegel dem Griechen darin, dass beide „ihre Welt sich zur Heimat gemacht“ hätten. ${ }^{22}$ Kants kosmopolitischer Deutscher weist zurück auf das achtzehnte, Hegels sich durch den „Geist der Heimatlichkeit“23 auszeichnender und durch den Antikeverweis legitimierter Deutscher greift auf die Geschichte des Begriffs im neunzehnten Jahrhundert vor, die ihn mit etwas spezifisch Deutschem, zugleich mythisch Überhöhtem in Verbindung bringt.

Dabei wurde auch zeitgenössisch die neue literarische Aufmerksamkeit auf Heimat als Wiederentdeckung und Neuinterpretation von Althergebrachtem ge-

20 Wielands Romanprotagonist wird 1766 nach den Umständen befragt, „welche dich in einem solchen Alter von deiner Heymath entfernt und in diese fremde Gegenden geführt haben können“. Wieland 1766, S. 318.

21 So in der Anthropologie in pragmatischer Hinsicht (1798), alle Zitate Kant 2004, S. 669.

22 Georg Wilhelm Friedrich Hegel: Vorlesungen über die Geschichte der Philosophie I, 1. Teil: Geschichte der Griechischen Philosophie; Einleitung, in: Hegel 1986, Bd. 18, S. 174. Hegel hielt die Vorlesungen über die Geschichte der Philosophie 1805/06 in Jena, 1816-1818 in Heidelberg und 1819-1831 in Berlin; auf der Grundlage von Notizen und Mitschriften wurden sie 1833-1836 postum herausgegeben.

23 So in den Vorlesungen über die Geschichte der Philosophie, Hegel 1986, Bd. 18, S. 174. 
deutet. Karl Philipp Moritz widmet die zwölfte Vorlesung seiner Vorlesungen über den Stil (1793/94) u. a. den veralteten Ausdrücken, von denen es einige wert seien, wieder in die literarische Sprache aufgenommen zu werden: ,Minne“ und ,Bieder‘ zählen nach Moritz genauso zu diesen Wörtern wie ,Heimat‘:

\begin{abstract}
Dieser veraltete Ausdruck verknüpft mit dem Begriff von Vaterland noch die Vorstellung von der häuslichen Ruhe und Glückseligkeit, der durch das schöne Wort heim in unserer Sprache angedeutet wird. / Wo man zu Hause ist, wenn man sich ruhig und wohl befindet, das nennt man seine Heimat; heimkehren, heimgehen, anstatt zu Hause kehren, sind daher schöne veraltete Ausdrücke, die mit Recht in unserer poetischen Sprache wieder aufgenommen sind, wo besonders der herrnhutische Ausdruck: er ist heimgegangen, anstatt er ist gestorben, dem Begriff, der damit verknüpft ist, eine außerordentliche Sanftheit gibt, und die Seele in eine wehmutsvolle, und doch ruhige Stimmung versetzt. / Darum faßt auch das Wort Heimat gleichsam einen Reichtum von dunkeln Begriffen und Empfindungen in sich, wodurch es eine Zierde und Schönheit unserer Sprache wird, die nur der verschmähen kann, der nie mit der ganzen Fülle der Empfindung ein solches Wort in seiner einfachen und schönen Bedeutung ausgesprochen hat, sondern bei dem die Idee die herrschende war, daß es doch ein veralteter Ausdruck oder Archaismus sei! ${ }^{24}$
\end{abstract}

Den „Reichtum von dunkeln Begriffen und Empfindungen“, den Moritz im Wort Heimat positiv hervorhebt, leitet er direkt aus dessen religiöser Bedeutung ab. Es gelte nun, das Wort wieder geläufiger zu machen, und das sei die Aufgabe der Literatur: „Veraltete Ausdrücke aber, die einmal von guten Schriftstellern gut gebraucht sind, muß man, zur Bereicherung unserer Sprache, auf alle Weise in Umlauf zu bringen suchen, damit das Ungewöhnliche sich nach und nach verlieret. “25 Genau diese von Moritz ausgelegte Fährte wird diese Arbeit verfolgen: Tatsächlich ist es die alte religiöse Bedeutung, die in die moderne, an „dunkeln Begriffen und Empfindungen" reiche Semantik von Heimat mit eingeht, und tatsächlich ist es vor allem die schöne Literatur, in der dies um 1800 vor sich geht.

Der erste Teil dieser insgesamt dreiteiligen Studie geht von der Beobachtung des religiösen Diskursursprungs der Heimat und dessen zentralen Stellenwerts für die Ausbildung der modernen Heimatsemantik aus. Bis zum Ende des 18. Jahrhunderts dominiert der religiöse Heimatbegriff in den überlieferten deutschsprachigen Textzeugnissen. ${ }^{26}$ Im Lauf des 19. Jahrhunderts tritt die geist-

24 Moritz 1981, S. 674.

25 Moritz 1981, S. 675.

26 Grundlage dieser Aussage ist die digitale Textsammlung des DTA. Bis zum 17. Jahrhundert erscheint Heimat hier ganz überwiegend in geistlichen Zusammenhängen; bis zum letzten Drittel des 18. Jahrhunderts machen die geistlichen Textzeugnisse noch etwa die Hälfte der Fundstellen aus. Insgesamt gilt, dass Textzeugnisse, gerade in den Epochen vor dem Zeitalter von Alphabe- 
liche Heimat gegenüber anderen Verwendungen des Begriffs zurück. Allerdings sind all diese neuen Heimatbegriffe ohne den religiösen kaum zu denken. Vor allem die Literatur tingiert den immanenten Begriff der Heimat als Ort der Herkunft mit dem religiösen Heimatbegriff. Das neu entstehende semantische Spektrum von Heimat wird zum Fundament aller seitdem ausgebildeten Heimatbegriffe. Es wäre dabei zu schwach argumentiert, dass die Literatur des frühen 19. Jahrhunderts die irdische Heimat mithilfe religiöser Elemente auratisiert. Heimat bleibt, so die stärkere These, in der Literatur der ersten Hälfte des 19. Jahrhunderts ein religiöser Begriff, und zwar einer, der auch das Irdische religiös färbt. Von Jung-Stilling über Hölderlin bis Eichendorff und Droste-Hülshoff kann Heimat ohne ihren religiösen Anteil schlicht nicht verstanden werden, andererseits erschöpft sich der Begriff aber nicht in der traditionellen christlichen Sprache einer himmlischen Heimat. Der erste Teil dieser Arbeit beleuchtet die Herkunft und die literarischen Transformationen dieses geistlichen Heimatbegriffs.

Die Literatur um 1800 bietet insgesamt ein uneinheitliches Bild in ihrem Umgang mit Heimat. Im Spätwerk der um 1800 noch schreibenden Aufklärer wie Wieland wird man Heimat kaum finden, und auch gern als ,Volksschriftsteller bezeichnete Autoren wie Johann Peter Hebel verwenden das Wort allenfalls ohne jede Emphase, in einem noch nicht ,modernen ${ }^{6}$ Sinn. ${ }^{27}$ Bei Herder, Schiller, Goethe oder Kleist wird der Begriff sehr sparsam, aber schon an einigen markanten Stellen eingesetzt. ${ }^{28}$ Sehr viel auffälliger ist sein literarischer Einsatz im Umfeld der Empfindsamkeit: bei Johann Gaudenz von Salis-Seewis oder Karl Philipp Moritz beispielsweise - rein quantitativ sind auch diese literarischen Funde nicht mit dem Umfang vergleichbar, in dem dann Hölderlin und die Romantik das Wort entdecken. Die semantische Neujustierung von Heimat, an der zwischen 1770 und 1840 gearbeitet wird, besteht ganz wesentlich in der Ver-

tisierung und Massenkultur, das u.a. auch alltagskulturelle Zeugnisse in ganz anderem Umfang vervielfältigt, nicht als Ausdruck von Alltagskultur misszuverstehen sind.

27 Johann Peter Hebel stellt im Schatzkästlein des rheinischen Hausfreundes (1811) fest: „[D]er Mensch hat sich überall ausgebreitet, wo nur ein lebendiges Wesen fortkommen kann, ist überall daheim, liebt in den heisesten und kältesten Gegenden sein Vaterland und die Heimath, in der er geboren ist“. Die lapidare Aussage, die anschließend die Ortsungebundenheit des Menschen als aus dem göttlichen Auftrag „Erfüllet (oder bevölkert) die Erde, und machet sie euch untertan“ abgeleitetes Faktum feststellt, steht in denkbar großem Kontrast zu den zeitgleich beginnenden Bemühungen, Heimat als schicksalhafte Geworfenheit des Menschen zu deuten. Hebel 1811, S. 61- 62 .

28 Neben den in der Arbeit besprochenen Stellen der genannten Autoren bei Schiller etwa in Die Räuber; vgl. dazu Blickle 2002, S. 88-89, oder in Wilhelm Tell, vgl. dazu Kittler 1986. Zu Kleists Hermannsschlacht vgl. Kittler 1986. 
schränkung alter religiöser Inhalte mit neuen Bedeutungsgehalten und einer neuen Relevanz, die dem Begriff beigemessen wird. Diesem Zeitraum, in dem der innovative Einfluss der Literatur auf die Heimatsemantik am größten war, gilt daher der historische Schwerpunkt des ersten Teils dieser Arbeit.

Die Religiosität, die im literarischen Heimatbegriff ab 1800 wirksam bleibt, beschränkt sich nicht auf die christliche Religion. Der neue Heimatbegriff erwächst vielmehr aus einer neuen Konstellation von Religion, Mythos und Kunst, die auch die antike Mythenwelt der homerischen Odyssee, mittelalterliche Legenden wie diejenige Ahasvers und neu geschaffene Mythen wie den des Fliegenden Holländers umfasst. Der Abschnitt zu ,Heimat und Mythos‘ trägt diesem Umstand Rechnung. Die sprachbildende Kraft, die der Odyssee-Übersetzung von Johann Heinrich Voß von 1781 zukommt, gilt auch für die semantische Verdichtung, die der Begriff der Heimat hier entfaltet. Die mythologische Figur des Odysseus steht fortan für eine teils allgemeinmenschliche, teils spezifisch deutsche Heimatsuche, der im gesamten 19. Jahrhundert selbst mythische Dimensionen zugeschrieben werden. Das Verhältnis des 19. Jahrhunderts zur Heimat zeigt sich auch am Mythos ihres Gegenteils - des heimatlosen Ahasver. Ahasver steht für den Zustand des Unsesshaftseins, des Ausgestoßenseins, vor allem aber des Judeseins. Sowohl der Antisemitismus und Antiziganismus, der sich im 19. Jahrhundert immer wieder latent mit Heimatvorstellungen verbindet, als auch jüdische Versuche der Selbstbehauptung gegenüber solchen Vorstellungen greifen mit dem Ahasver-Mythos auf Heimatbilder der Zeit zurück und prägen sie selbst mit, was auch an der Odysseus und Ahasver verbindenden Kunstfigur des Fliegenden Holländers (1843) von Richard Wagner gezeigt werden kann.

Die 1840er Jahre bilden schwerpunktmäßig den historischen Abschluss des ersten Teils. Auch über diese Zeit hinaus bleibt Heimat als religiöses Konzept bestehen und prägt Heimatvorstellungen immanent bis heute. Aber die 1840er Jahre bilden in vielfältiger Hinsicht eine Zäsur, die sich etwa in Ludwig Feuerbachs für die bürgerlichen Realisten einflussreicher Religionsphilosophie äußert. Religion wird hier als dem menschlichen Bedürfnis entspringend und auf dieses zielend verstanden; Gott existiert, insofern er ein Spiegel des menschlichen Bedürfnisses ist. Auch die himmlische Heimat erscheint von diesem Standpunkt aus als eine anthropologischer Bedürftigkeit entspringende Konstruktion. Feuerbach schreibt 1841:

Jeder Mensch muß sich daher einen Gott d.h. einen Endzweck setzen. Der Endzweck ist der bewußte und gewollte wesentliche Lebenstrieb, der Genieblick, der Lichtpunkt der Selbsterkenntniß - die Einheit von Natur und Geist im individuellen Menschen. Wer einen Endzweck, hat ein Gesetz über sich: er leitet sich nicht selbst nur; er wird geleitet. Wer keinen Endzweck, hat keine Heimath, kein Heiligthum. [...] Wer einen Zweck hat, einen Zweck, der an sich wahr und wesenhaft ist, der hat darum eo ipso Religion - wenn auch nicht im Sinne 
der gewöhnlichen, der herrschenden Religion, aber doch im Sinne der Vernunft, der Wahrheit, der universellen Liebe, der allein wahren Liebe. ${ }^{29}$

Die Vorstellung einer himmlischen Heimat erscheint bei Feuerbach als ein den Menschen leitender religiöser ,Endzweck', oder andersherum: Ohne die Vorstellung eines Gottes hat der Mensch auch keine Heimat. Die himmlische Heimat ist mit Feuerbach somit eine religiöse Vorstellung, die ihren Ursprung in der reinen Immanenz hat. In gewisser Weise ist damit der Endpunkt einer religiösen Heimatvorstellung erreicht. In anderer Perspektive ermöglicht die Immanenz religiöser Vorstellungen das Weiterleben transzendenter Heimatbegriffe bis in unsere eigene unmittelbare Gegenwart.

Der zweite Teil der Arbeit wendet sich der heute fast vollkommen vergessenen rechtlich-administrativen Bedeutung von Heimat zu. Wie bei der religiösen liegen auch die Ursprünge der rechtlichen Bedeutung weit vor dem 19. Jahrhundert und wie bei jener bezeichnet auch bei dieser das 19. Jahrhundert den Zeitraum ihrer semantischen Dynamisierung.

Rechtlich bezeichnete Heimat eine administrative Einheit, mit der sich Versorgungsrechte und -pflichten verbanden. Das Heimatrecht regelte vornehmlich die Zuständigkeit der Gemeinden für die Versorgung der Armen sowie deren Abschiebung aus allen nicht zuständigen Gemeinden. Es war in den deutschsprachigen Ländern mindestens bis zum Ende des 19. Jahrhunderts, teilweise weit darüber hinaus, gültig und selbstverständliches Alltagswissen. Wenn in alltagssprachlichen Verwendungen der Ort individueller Herkunft als Heimat bezeichnet wird - ob weiter oder enger, geographisch oder sozial gefasst -, schwingt daher auch die rechtliche Bedeutung mit. Auch das regional noch im 19. Jahrhundert fortlebende ökonomische Verständnis von Heimat als dem Hof, den man besaß oder erwarb - „Das neue Heimath kostet ihn wohl 10,000 Gulden“, heißt es bei Jeremias Gotthelf $f^{30}$, fügt sich in ein Verständnis von Heimat, in dem es um ökonomische Sicherheit und Versorgung geht.

Das Heimatrecht wurde im 19. Jahrhundert zunehmend dysfunktional, weil es die Versorgung Bedürftiger an Orte und Gemeinden band, in denen die Bedürftigen zum größeren Teil gar nicht mehr lebten. Angesichts steigender Mobilität war der Herkunftsort für viele nicht mehr deckungsgleich mit dem tatsächlichen Aufenthaltsort. Zugleich stieg in Zeiten des Pauperismus der Bedarf an ökonomischer Unterstützung. Bedürftige, Bettelnde und Vagabundierende wurden auf

29 Feuerbach 1841, S. 71.

30 Gotthelf 1854, S. 19. Das Zitat aus dem Roman Erlebnisse eines Schuldenbauers (1854) wird in der Forschung seit Bausinger 1980 und Jens 1985 immer wieder herangezogen. 
Grundlage des Heimatrechts zwangsweise in ihre Heimatgemeinden abgeschoben. In dem Maß, in dem das bestehende Heimatrecht angesichts der immer dringlicher werdenden sozialen Fragen zum Inbegriff sozialer Härte, staatlicher Ignoranz und administrativer Borniertheit wird, konterkariert es aber den emphatischen Heimatbegriff, der sich parallel seit der Empfindsamkeit ausgebildet hatte. Die öffentliche Debatte um das Heimatrecht, die ab Mitte des 19. Jahrhunderts zunehmend vehement geführt wurde, spiegelt diese Widersprüche zwischen der pragmatischen, rechtlichen Bedeutung und einem emotional besetzten Heimatverständnis wider.

Auch die neue realistische Literatur macht den Widerspruch zwischen einem anachronistisch gewordenen Heimatrecht und einem emphatischen Heimatverständnis ab den 1840er Jahren mit ganz unterschiedlichen Intentionen und Effekten zum Problem. Von Fritz Reuter bis Friedrich Gerstäcker werden nicht nur die Verwerfungen des Heimatrechts zum literarischen Sujet. Es geht, etwa bei Berthold Auerbach oder Hermann Kurz, um die Spannung, die sich aus den widersprüchlichen Semantiken einer pragmatischen Rechtsheimat und einer emphatisch verstandenen Heimat ergibt. In der neu sich ausbildenden literarischen Heimatsemantik um 1800 spielte das Heimatrecht zunächst so gut wie keine Rolle. Erst die realistische Literatur, die Alltagswelt zum Modell ihrer literarischen Welten macht, konkretisiert auch Heimat in diesem Sinn in ihrer pragmatischen Bedeutung. Gleichzeitig entwickelt die realistische Literatur Erzählmodelle, nach denen die Idee der Heimat auch der poetischen Überhöhung des Alltäglichen dienen kann. Der historische Schwerpunkt des zweiten Teils liegt daher im Zeitraum der Ausbildung des bürgerlichen Realismus, also auf der Mitte des 19. Jahrhunderts; insbesondere zwischen 1840 und 1865 geschriebene literarische Texte stehen im Zentrum der Aufmerksamkeit.

Die realistische Literatur ist vor allem bürgerliche Literatur und das selbstverständliche Alltagswissen des 19. Jahrhunderts um die rechtliche Dimension von Heimat umfasste auch das Wissen, dass es Heimat im rechtlichen Sinn nicht für alle gab. Das angebliche Bewusstsein des 19. Jahrhunderts von Heimat „als dem unzerstörbaren und unverlierbaren Besitz eines Jeden“31 ist ein Missverständnis gegenwärtiger Forschungen zur historischen Bedeutung von Heimat. Tatsächlich waren die armen Bevölkerungsschichten stets von Heimatlosigkeit bedroht. Ob jemand Heimat hatte oder im juristischen Sinn heimatlos war, richtete sich nicht zuletzt nach dem Status des Einzelnen in der bürgerlichen Gesellschaft. Das Bürgertum verteidigte seine Heimat nach unten und nach oben. Die Armen waren von rechtlicher Heimatlosigkeit bedroht und die latenten Ab-

31 Pohlheim 2007, S. 240; vgl. auch Moosmann 1980, S. 46. 
stiegsängste des Bürgertums manifestierten sich auch in der Angst, Heimat zu verlieren, wie die literarischen Texte Adalbert Stifters und Gottfried Kellers vorführen. Der Adel wurde dagegen topisch der ideellen Heimatlosigkeit des Kosmopolitismus bezichtigt. Reiche mussten das Heimatrecht nicht in Anspruch nehmen und konnten sich ihren Kosmopolitismus zusammen mit ,inglish cottage، und ,englischem Rasen' leisten, wie die späte Bettina von Arnim in Dies Buch gehört dem König (1843) schreibt. Nach ihrer Ansicht sollten sie aber besser den heimatlosen Armen aus ihrem Elend helfen. Die Entscheidung zwischen Kosmopolitismus und Patriotismus erscheint als eine Frage des Geldes und der Umgang mit der verarmten, heimatlosen Bevölkerung als Seismograph:

Soll der Adel Euch adeln den mit Wucherglück der Bürger seiner Abkunft zum Hohn im adlichen Gute sich ankauft; so mach er statt Luxus-Anlagen von Tempel und Grotte und tanzenden Wassern, - Anlagen für Heimatlose, und sein Sommerplaisir die inglish cottage mach er zur deutschen Hütte worin deutsche Armut sich erholt; den englischen Rasen teil er aus zu Feldern für Kartoffel und Brot und er ist Edelmann, wer wird widersprechen. ${ }^{32}$

Wenn hier das kosmopolitische Luxusleben der Reichen und das Elend der heimatlosen Armen miteinander konfrontiert werden, steht Heimat-Haben für eine gesellschaftliche bürgerliche Mitte, die sich im Zitat gleich zweimal auch mit dem ,Deutschen' verbindet: nicht englischer Rasen, sondern Kartoffelfelder gegen ,deutsche Armut', nicht ,inglish cottage‘, sondern ,deutsche Hütte'. Heimat ist insofern auch bei der Adligen von Arnim ein programmatischer Begriff des Bürgertums, das sich im 19. Jahrhundert immer auch als patriotisch begreift.

Das öffentliche und literarische Interesse am Heimatrecht ist ein Indikator für eine zunehmende Konkretisierung und Materialisierung von Heimat ab Mitte des 19. Jahrhunderts. So wie Heimat materielle Versorgung bedeuten kann, kann sie auch das sein, was sich konkret anfassen lässt: Auf Heimat als unmittelbar wahrnehmbare und erfahrbare Umgebung zielen schon die pädagogischen Konzepte der ,Heimatkunde، am Beginn des 19. Jahrhunderts. Diese Auffassung von Heimat steht aber zu diesem Zeitpunkt noch recht unverbunden neben zumindest in der Literatur vorherrschenden religiös gefärbten, außerhalb von Zeit und Raum stehenden Heimatvorstellungen. Ab den 1840er Jahren wandelt sich dieses literarische Verständnis; Heimat bindet sich auch in literarischen Beschreibungen zunehmend an konkrete Gegenstände und materielle Güter, die „Bretter, Pfähle und Truhen“, wie etwa bei Adalbert Stifter nachzulesen ist:

Es ist dies die Dichtung des Plunders, jene traurig sanfte Dichtung, welche bloß die Spuren der Alltäglichkeit und Gewöhnlichkeit prägt, aber in diesen Spuren unser Herz oft mehr

32 Arnim 1995, S. 330. 
erschüttert, als in anderen, weil wir auf ihnen am deutlichsten den Schatten der Verblichenen fort gehen sehen, und unsern eignen mit, der jenem folgt. Darum hat der Großstädter, der stets erneuert, keine Heimat, und der Bauerssohn, selbst wenn er Großstädter geworden ist, hegt die heimliche sanft schmerzende Rückliebe an ein altes schlechtes Haus, wo die Bretter, Pfähle und Truhen seiner Voreltern standen und stehen. ${ }^{33}$

Dass da allerdings etwas dingfest gemacht werden soll, was sich zunehmend entzieht, ist schon diesem Zitat zu entnehmen, denn es ist ja die Mappe des Urgroßvaters, um die es bei Stifter geht, also etwas Altes, beinahe Vergessenes, und aus den Bauern sind Großstädter geworden, deren Bezug zur Heimat eine ,heimliche sanft schmerzende Rückliebe' geworden ist. Aber je mehr sich das vermeintlich Vergangene entzieht, desto stärker werden die Bemühungen, es zurückzugewinnen, und so beginnt die eigentliche Heimatkonjunktur Mitte des 19. Jahrhunderts im Kontext einer sich zunehmend industrialisierenden Lebenswelt. Um 1900 kann man dann von einem regelrechten ,Heimat-Hype ${ }^{634}$ sprechen. Die Hypertrophierung des Heimatbegriffs umfasst um 1900 praktisch alle Lebensbereiche: von volkskundlichen, landeshistorischen, pädagogischen, architekturtheoretischen, kunstprogrammatischen und literarischen Schriften, von Liedtexten über Kunstpostkartendrucke bis zu Programmen zu Landschaftsschutz und Leibesübungen - nie war so viel Heimat in deutschsprachigen Textzeugnissen zu finden. Heimat ist ein Schlüsselbegriff unzähliger kultureller Debatten, populärer und wissenschaftlicher Diskurse. Die Semantik von Heimat umfasste um 1900 dabei sehr Unterschiedliches: Sie verband sich mit Nostalgie angesichts des Verlusts einer vorindustriellen Zeit, aber auch mit Vorstellungen großstädtischer Heimaten; sie verband sich mit deutschnationalen und völkischen Positionen, aber auch mit anschauungsbasierten Unterrichtsmodellen oder ökologisch motivierter Abkehr von den zerstörerischen Seiten der Industrialisierung. Sie verband sich mit der Rückbesinnung auf vorkapitalistische Traditionen, aber auch mit handfestem ökonomischem Gewinn. ${ }^{35}$

33 Stifter 1966, S. 388. Die Mappe meines Urgroßvaters ist hier in der Fassung von 1841 zitiert. 34 Vgl. Costadura/Ries 2016, S. 12.

35 Der Historiker Alon Confino beschreibt, wie Wiederentdeckung und Vermarktung traditioneller Trachten in dem württembergischen Dorf Betzingen miteinander zusammenhingen. Über Bilder und Fotografien verbreitet, wurden die für diesen Zweck neu hergestellten Trachten vor allem am Wochenende für die Touristen getragen, die über eine gute Zugverbindung aus den Städten Reutlingen und Tübingen anreisten. Diejenigen, die diese Trachten als touristische Attraktion trugen, waren vornehmlich Männer des Dorfes, die wochentags selbst als Fabrikarbeiter in den näher gelegenen Städten arbeiteten (vgl. Confino 1997, S. 116-117). Der nach Confino von der städtischen Bourgeoisie erdachte Begriff ,Tracht‘ wurde von den Bauern nicht einmal verstanden (vgl. Confino 1997, S. 116). Folklore in Form von ,heimatlichen', regionalen Trachten und 
Insgesamt ist aber trotz dieser evidenten Pluralisierung von Heimat ein Heimatverständnis vorherrschend, das im Singular spricht. Nicht die Diversität von Heimaten - seien es unterschiedliche landschaftliche Regionen oder kulturelle Prägungen, seien es unterschiedliche Konzepte von Heimat -, sondern ihre Subsumierung zu der einen deutschen Heimat ist das auffälligste Signum der Epoche. Die Diffusion der rechtlichen Heimatsemantik von der Gemeinde zu Staat und Nation hat alle gesellschaftlichen Bereiche erfasst. Symptomatisch ist ein landeskundlicher Bildband von August Sachs: Die deutsche Heimat. Landschaft und Volkstum von 1885, in vielen weiteren Auflagen bis ins 20. Jahrhundert verbreitet, der eben nicht von den vielen regionalen Heimaten, sondern von der einen deutschen Heimat spricht. ${ }^{36}$

Auffällig ist auch die steigende Anzahl von Versuchen einer ,Theoretisierung“ von Heimat, und so gilt der dritte Teil der Arbeit den Bemühungen der Wissenschaften, Heimat dingfest zu machen, wobei das Kapitel zwar mit dem Beginn des 19. Jahrhunderts einsetzt, seinen historischen Schwerpunkt aber im letzten Jahrhundertdrittel und der Zeit um 1900 hat. Für die wissenschaftlichen Heimatkonzepte wurden hier repräsentativ die Pädagogik, die Volkskunde und die Literaturgeschichtsschreibung ausgewählt. All diese Disziplinen stehen in mehr oder weniger engem Bezug zur ,Germanistik` und daher kann dieses Kapitel auch als Beitrag zur Fachgeschichte gelesen werden.

Für Pädagogik und ,Deutschkunde“ wird Heimat zum Universalschlüssel, der wissenschaftlicher Objektivität genügen soll: „Ähnlich wie es einen politischen oder einen Rechtsbegriff der Heimat giebt, wird es gut sein, gleichsam einen Schulbegriff derselben aufzustellen“, fordert ein pädagogisches Lexikon am Ende des Jahrhunderts. ${ }^{37}$ Heimat wird als umfassendes Leitprinzip der Wissenschaften verstanden. Die Pädagogik empfiehlt, Heimat als fächerübergreifendes Unterrichtsprinzip zu verstehen. ${ }^{38}$ Jede Schule solle ihren eigenen „Heimatgarten“, ihr eigenes „Heimatzimmer“, ja ihr eigenes „Heimatmuseum“ errichten, jeder Lehrer

\footnotetext{
Bräuchen wurde demnach nicht nur entdeckt, um sie zu bewahren, sondern auch befördert oder gar erfunden, weil sie ökonomisch lukrativ war. In diesem Sinn ist ,Heimat“ nicht das Gegenteil der (kapitalistischen, entfremdeten) Moderne, sondern eben auch immer ihr Produkt. Vgl. dazu den Beginn des Romans von Riehl, Ein ganzer Mann, in dem ein ,Verein zur Hebung des Fremdenverkehrs' seine ,Heimatliebe‘ zu Markte trägt (vgl. II.3.2.2).

36 So auch die These von Schumann 2002.

37 Scholz 1897, S. 401.

38 Mit den Richtlinien für die Lehrpläne der höheren Schulen Preußens von 1925 werden diese schon früher ausgebildeten Prinzipien schulpolitisch gestärkt. In einem pädagogischen Artikel von 1928 wird mit Bezug auf die Richtlinien ausgeführt, dass „,heimatkundliche Einstellung fast allen Fächern eigen ist“ und es zur „Pflicht“ geworden sei, „Heimat im Unterrichte in jeder Weise zu Worte“ kommen zu lassen. Held 1928, S. 7.
} 
„Heimatkundeunterricht“ inklusive „Heimatwanderungen“ durchführen. ${ }^{39}$ Heimatkunde soll nach dem Willen vieler Pädagogen zu einer gänzlichen „Neugestaltung der Schule im Sinne des Heimatgedankens" führen und neben Deutschunterricht und Erdkunde genauso in Religionsunterricht, Mathematik, ,Nadelarbeit' und ,Leibesübungen“ eine Rolle spielen. ${ }^{40}$

Auch für die sich im letzten Drittel des 19. Jahrhunderts formierende Volkskunde ist Heimat ein Schlüsselbegriff. Heimat fungiert einerseits als objektivierbarer Beschreibungsgegenstand des Fachs und andererseits als dessen Ideal, das es zu erhalten, zu bewahren und wiederzubeleben gilt. Die Volkskunde nationalisiert Heimat, indem sie diese zum spezifisch deutschen Gemütswert erklärt. Dieser volkskundliche Heimatbegriff hat Strahlkraft auch auf andere Disziplinen wie die Germanistik und die Geschichtswissenschaft und ihre Didaktik. Der Anspruch auf Wissenschaftlichkeit, den die Volkskunde für ihren Umgang mit Heimat erhebt, wirkt ab 1900 insbesondere auch auf die Literaturgeschichtsschreibung. Literaturhistorische Ansätze wie die von August Sauer oder Josef Nadler wären ohne das volkskundliche Heimatverständnis nicht denkbar. Zur wissenschaftlichen Leitkategorie wird Heimat bei Adolf Bartels, der die sogenannte Heimatkunstbewegung zum (vorläufigen) Telos der deutschen Literaturgeschichte erklärt.

Den Leitdiskurs in Sachen Heimat haben dabei schon längst andere gesellschaftliche Felder übernommen: Heimat existiert in nahezu allen Lebensbereichen mit eingeführten Begriffen als Heimatarchitektur, Heimatschutzbewegung, Heimatverein, Heimatverlag, sie ist Teil der populären wie der Expertensprache und nur noch unter anderem auch Teil der literarischen Sprache. Die Funktion der Literatur besteht nun eher darin, andere Heimatdiskurse zu legitimieren. So fällt auf, dass die Volkskunde oder die Pädagogik ihre These von der spezifischen Heimatliebe der Deutschen gerade an literarischen Beispielen belegen. Heimat wird von wissenschaftlichen Diskursen als „zu dem Subjektivsten des Menschenlebens“ gezählt, sie ist ein „Gefühlswert“ und gehört dem Bereich des Menschlichen an, „in dem wir alle Poeten sind“. ${ }^{41}$ Heimat und Literatur bleiben also auch in ganz anderen Zusammenhängen als den eigentlich literarischen aufs engste verknüpft. Ein großer Teil der zeitgenössisch produzierten literarischen

39 Alle Zitate Held 1928, S. 7.

40 Walther Schoenichen: Vorwort, in: Schoenichen 1924, S. V-VI, hier S. V. Das von Schoenichen herausgegebene Handbuch der Heimaterziehung enthält Beiträge zu sämtlichen Unterrichtsfächern, neben den genannten auch zu ,Heimatkunde und Heimatschutz im Zeichenunterricht‘, ,Heimaterziehung im hauswirtschaftlichen Unterricht" und so fort.

41 Eduard Spranger: Der Bildungswert der Heimatkunde, in: Schoenichen 1924, S. 3-26, hier S. 3. 
Heimatdarstellungen dient gewissermaßen dem Nachweis dieser Auffassung, indem er sie perpetuiert, klischiert und popularisiert. Aber natürlich kann Literatur zeitgleich auch weiterhin ein ästhetisch-innovatives oder kritisches Verhältnis zu zeitgenössischen Heimatentwürfen einnehmen - oder sie kann auch beides zugleich: Heimatklischees bedienen und befragen. ${ }^{42}$

\subsection{Geschichte der Heimat und Geschichte der Literatur}

Die hier verfolgte Hypothese, die semantische Dynamisierung und Neufunktionalisierung von Heimat habe in den 1770er Jahren begonnen und ihre Bedeutung für die verschiedenen gesellschaftlichen Diskurse sei bis zu ihrem vorläufigen Höhepunkt um 1900 angewachsen, deckt sich mit den quantitativen Verlaufskurven der Diagramme, die sich mithilfe digitaler Datenbanken erstellen lassen. Die Verlaufskurve des Deutschen Textarchivs etwa zeigt die im historischen Ausschnitt zwar kurvenreiche, auf längere Sicht aber stetig ansteigende Linie der quantitativen Bedeutung von Heimat in deutschsprachigen Schrifterzeugnissen (Abb. 15). ${ }^{43}$ Die nach Textsorten aufgeschlüsselte Verlaufskurve des DTA zeigt zudem, dass der Aufstieg von Heimat in der Literatur besonders auffällig ist (Abb. 16).

Die stärkste Rolle spielt Literatur für die Ausbildung einer modernen Heimatsemantik zwischen 1770 und 1840. In dieser Zeit ist es die Dichtung, welche der Heimat ihre neue semantische Schubkraft verleiht. Die Geschichte der Heimat ist in diesem Sinn vor allem in ihren Anfängen eine Geschichte der Literatur. Li-

42 In Bezug auf die omnipräsente Behauptung des (in dieser Hinsicht sehr langen) 19. Jahrhunderts, Heimatliebe sei etwas spezifisch Deutsches, zeigt die Novelle Heimatluft (1901) der Gartenlauben-Autorin Marie Bernhard diese doppelte Lesbarkeit von literarischen Texten. Eine Figur im Text bestreitet die Behauptung, Heimatliebe gehöre zum Deutschsein, gegenüber einem vermeintlichen Amerikaner - „Die Leute tun immer so, als hätten wir Deutschen die Heimatliebe extra gepachtet. Unsinn, sag’ ich! Das liegt im Menschen, und damit Punktum!“ -, der sich im weiteren Erzählungsverlauf allerdings als so heimatverbunden wie deutsch entpuppt und auf diese Weise das Klischee des heimatliebenden Deutschen eher stützt als unterläuft. Bernhard 2018, S. 120.

43 Auch das größere Textkorpus in Google’s Ngram Viewer zeigt ähnliche Ergebnisse: https:// books.google.com/ngrams/graph?content=Heimat\&year_start=1800\& year_end=2019\&corpus= 31 (letzter Zugriff 10. Mai 2021). Beide Statistiken können nur als Indikatoren verwendet werden im Fall des DTA ist die Quellenanzahl recht gering, im Fall des Ngram Viewer unterliegt die Textauswahl nicht dem Kriterium der Repräsentativität, auch ist die Zunahme von Druckerzeugnissen insgesamt in die Bewertung der Statistik einzubeziehen. Aber als Hinweis auf die zunehmende Präsenz von Heimat in deutschsprachigen Texten des 19. Jahrhunderts kann man die Statistiken allemal verstehen. 
Verlauf: 'heimat'; relative Häufigkeit: 40.36 Vorkommen pro 1 Mio. Tokens

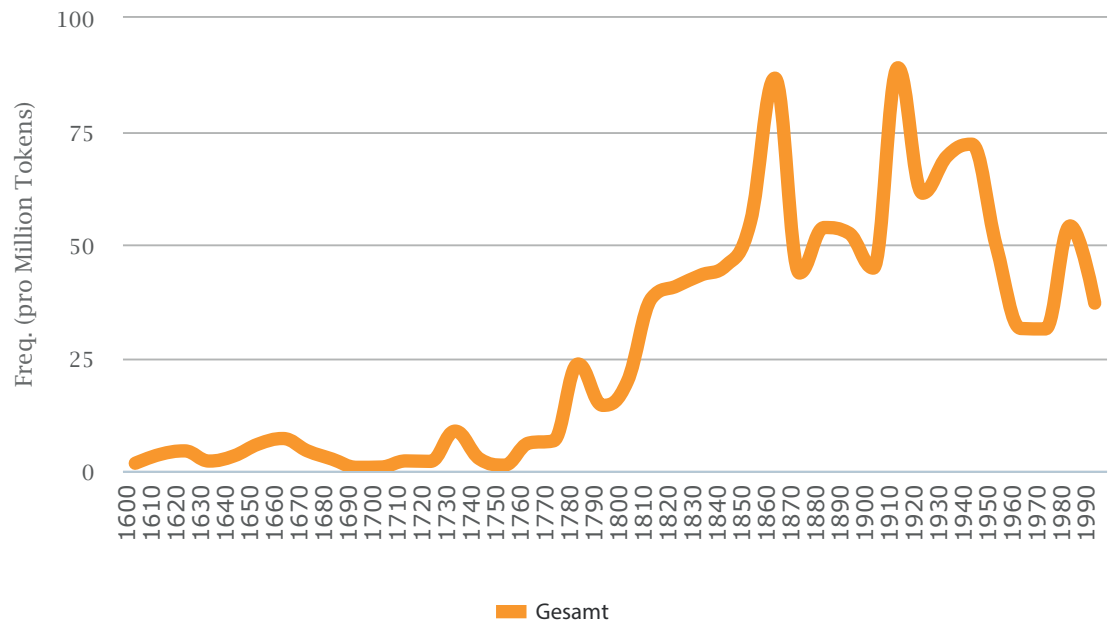

Abb. 15: Verlaufskurve „Heimat“ der DTA-Korpora und des DWDS-Kernkorpus. Deutsches Textarchiv. URL: https://www.deutschestextarchiv.de/ (letzter Zugriff 30.9.2021)

teratur übernimmt im Lauf des langen 19. Jahrhunderts dann sehr unterschiedliche Funktionen für die Ausbildung des neuen Heimatverständnisses. Sie kann in Bezug auf Heimat zugleich kultureller Wissensspeicher und ästhetisches Reflexionsmedium sein. Innerhalb solcher Speicher- und Reflexionsprozesse entstehende literarische Heimatvorstellungen wirken wieder zurück auf nicht-literarische Semantiken von Heimat: In der Literatur um 1800 ausgebildete Heimatvorstellungen lassen sich am Ende des Jahrhunderts wieder in juristischen und religiösen Texten zu finden; volkskundliche und pädagogische Texte legitimieren ihren Gegenstand unter Bezugnahme auf literarische Heimattexte und so fort. In der Genese von Heimat stellt sich dieses Wechselverhältnis der Semantiken sehr unterschiedlich dar. In der Literatur generierte Vorstellungen von Heimat prägen durch das gesamte 19. Jahrhundert (und in der Folge) gesellschaftliche Debatten ${ }^{44}$ literarische Bestseller wie Gustav Freytags Ahnen wirken auf Heimatvorstellungen ganzer Schülergenerationen ein. Und es ist kein Zufall, dass Konzepte von Heimat um 1900 insbesondere in literarischen Bewegungen wie der sogenannten Heimatkunst ihren Ausdruck fanden und es eine wahre Flut litera-

44 Vgl. auch Scharnowski: Heimat, 2019, S. 13. 


\section{Verlauf: 'heimat'; relative Häufigkeit: 40.36 Vorkommen pro 1 Mio. Tokens}

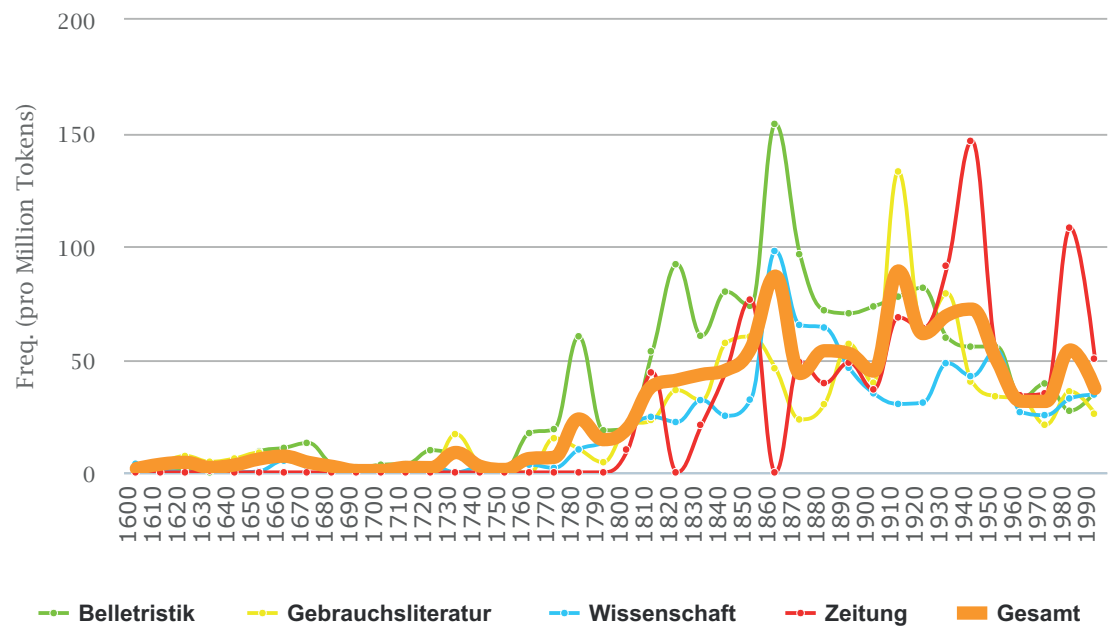

Abb. 16: Verlaufskurve „Heimat“ der DTA-Korpora und des DWDS-Kernkorpus, aufgeschlüsselt nach Textkategorien. Deutsches Textarchiv. URL: https://www.deutschestextarchiv.de/ (letzter Zugriff 30.9.2021)

rischer Texte gibt, die Heimat um 1900 schon im Titel tragen: Romane und Erzählungen, ${ }^{45}$ Gedichtbände und -anthologien, ${ }^{46}$ Theaterstücke ${ }^{47}$ und Lesebücher

45 Für Romane und Erzählungen vgl. Fritz Bley: Ans Herz der Heimat (1883), Karl Stieler: Aus Fremde und Heimat (1886), Hermine Villinger: Aus meiner Heimat (1887), Emil Frommel: Aus der Heimat für die Heimat (1888), A. von Hedenstjerna: Aus der Heimat. Bilder und Skizzen (1891), Peter Rosegger: Spaziergänge in der Heimat (1894), Hermann Tiemann: Aus Heimat und Jugend. Bilder und Skizzen aus der engeren und weiteren Heimat (1895), Armin Stein: Aus der Heimat. Schlichte Geschichten (1895), Elisabeth Halden (d.i. Agnes Breitzmann): In Heimat und Fremde (1897), Hans Nikolaus Krauß: Heimat (Romantrilogie, 1897-1902), Andrä Heinrich Fogowitz: Fern der Heimat (1899), Ludwig Ganghofer: Aus Heimat und Fremde (1899), Goswina von Berlepsch: Heimat. Schweizer Novellen (1899), Horst Bodemer: Heimat. Roman (1900), Hermann Petrich: Heimat und Fremde. Zwölf deutsche Männer (1900), Fritz Boré: Wie mich die Heimat grüßte (1900), Heinrich Seidel: Heimat. Geschichten (1902), Franz Werner: Heimatluft. Briefe aus der Ostmark (1903), Helene Schock: Eine Heimat. Familienbilder (1903), Paul Keller: Die Heimat (1904), Rudolf Hawel: Aus meiner Heimat. Novellen (1904), Arthur Schubart: Neues aus meiner Heimat. Hochlandgeschichten (1905), Sophie von Niebelschütz: Das Glück der Heimat (1905), Johannes Wehrmann: Menschen ohne Heimat. Roman (1906), Theodor Storm: Briefe in die Heimat (1907), Helene Reimer: Aus Heimat und Kinderland. Novellen (1909), Anna Blum: Ohne Heimat (1910), Paul Keller: Die 
für den schulischen Gebrauch. ${ }^{48}$ Insgesamt gilt, dass die herausgehobene Stellung der Literatur für die Formung des Heimatdiskurses im Lauf des 19. Jahrhunderts durch andere Diskursgeneratoren wie die Volkskunde oder die sogenannte Heimatkunde abgelöst wird, diese Disziplinen sich aber an zentralen Stellen auf literarische Texte beziehen. Bis ins 20. und 21. Jahrhundert ist, wenn über Heimat reflektiert wird, Dichtung der maßgebliche Bezugspunkt; Heimat und Dichtung gehören daher auch aus der Perspektive anderer Disziplinen eng zusammen. ${ }^{49}$

Insofern ist die Geschichte der Heimat einerseits auch eine Geschichte der Literatur, andererseits kann sie nicht ausschließlich als literaturhistorische Studie geschrieben werden, sondern muss den diskursiven Verflechtungen des Begriffs auch in ganz anderen gesellschaftlichen Bereichen nachgehen. Anschaulich wird dies beispielsweise an den Ersterscheinungsorten einer ganzen Reihe von hier herangezogenen literarischen Texten: der Familienzeitschriften. Diese Periodika waren als Unterhaltungs- und Bildungsmedien konzipiert und gut mit den Fachwissenschaften vernetzt. Die Durchsicht solcher für die Herausbildung der bürgerlichen Kultur des 19. Jahrhunderts ganz zentralen Medien macht nicht nur quantitativ die Bedeutung von Heimat für das bürgerliche Publikum evident. Sie zeigt zudem, warum man über einen Heimatbegriff der Literatur des 19. Jahr-

Heimat. Roman (1910), F. W. Liebrich: Um die Heimat. Roman (1910), Pauline Schanz: Fern der Heimat (1910), Georg Freiherr von Ompteda: Heimat des Herzens. Roman (1910), Adam MüllerGuttenbrunn: Glocken der Heimat (1911).

46 Vgl. Ludwig Bund (Hg.): Lieder der Heimat (1882), Gustav Weck (Hg.): Von Heimat zu Heimat. Ein Lebensbuch in Liedern (1890), Georg von Rohrscheidt: Schwert und Heimat. Gedichte (1898), August Bender: Die himmlische Heimat (1900), Fr. Gillhoff: Lichter der Heimat. Gedichte (1900), August Storch: Heimat und Vaterland. Gedichte (1902), H. Hugendubel: Aus der Heimat in die Heimat (1902), Margareta Iselin: Aus Heimat und Fremde (1903), B. Hummel: Aus meiner Heimat. Gedichte (1904), Anonym (Hg.): Unsre Heimat. Baltische Lieder (1906), Anonym (Hg.): Liederbuch für Front und Heimat (1907), David Merkens: Heimat (1910); M. Trümpelmann: Waldeszauber. Gedichte. Meiner lieben Heimat Thüringen (1910).

47 Vgl. Paul Munkelt: O Heimat, süße Heimat. Salonstück (1890), Hermann Sudermann: Heimat (1893), Karl Schönherr: Glaube und Heimat (1910), zu Karl Schönherr vgl. Riedmann 1991, S. 110 116.

48 Vgl.W. Jütting, Hugo Weber (Hg.): Die Heimat (1893), Paul Heidelbach (Hg.): Hessische Heimat. Ein literarisches Heimatbuch (1901), Karl Limberger (Hg.): Aus der Heimat - über die Heimat. Lesestücke für badische Schulen (1905), Robert Guenther (Hg.): Die deutsche Heimat (1908), Richard von Kralik (Hg.): Heimat-Erzählungen aus alter Zeit (1909), Richard von Kralik (Hg.): HeimatErzählungen aus neueren Zeiten (1910), Beckhusen (Hg.): In der Heimat. Märchen, Sagen, Bilder (1910).

49 Vgl. exemplarisch Martin Heideggers Aufsatz Sprache und Heimat (1960), der sich vor allem mit literarischen Texten auseinandersetzt (vgl. Heidegger 1983). Erst Wilhelm Brepohl sieht in literarischen Heimatvorstellungen eine Gefahr für die Objektivierung des Begriffs: Die Auffassung von Heimat sei „durch die Literatur verdorben“. Brepohl 1965, S. 43. 
hunderts (und darüber hinaus) nicht nachdenken kann, ohne zugleich den der Volkskunde, der Pädagogik, des Rechts, der Religion, ja den der Botanik, Mode oder Werbung (Abb. 17), aber auch der literarischen Kritik mit zu berücksichtigen.

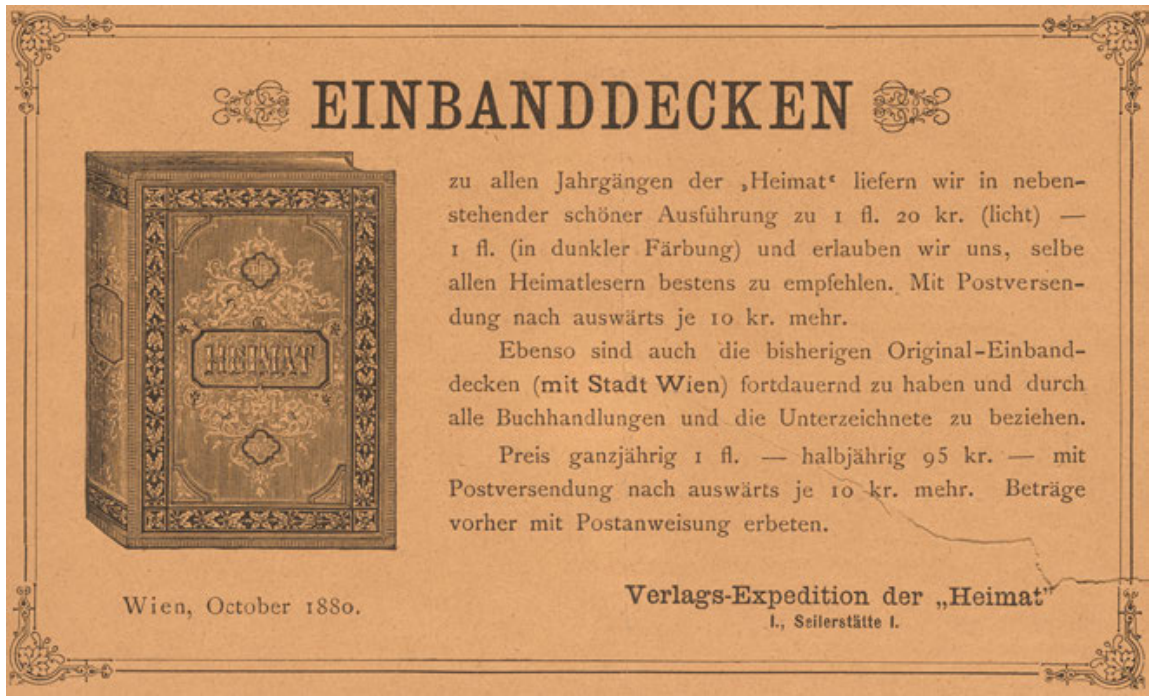

Abb. 17: Werbeanzeige für Einbanddecken. In: „Die Heimat. Illustrirtes Familienblatt“, VI. Jg., 1. Heft (1881) (Klassik Stiftung Weimar)

Denn literarische Heimattexte werden ganz konkret im Kontext anderer, nichtliterarischer Heimatbegriffe publiziert und beides wirkt aufeinander ein. Um zwei Beispiele aus populären Familienzeitschriften der Zeit zu geben: In der Gartenlaube des Jahres 1864 erscheint Friedrich Gerstäckers Novelle Der Heimathschein (vgl. II.2.2.2) neben einem volkskundlichen Artikel über die „alten Bräuche der Heimath“, ${ }^{50}$ einer Warnung vor den Gefahren der Auswanderung, die viele „arm und elend in die Heimath zurück[kehren] “51 lasse, und einer Apologie auf den Abgeordneten Ludwig Häusser, dessen Stimme an die „Feiertagsglocken der Heimath“552 erinnere. Die alltagssprachlichen Verwendungen von Heimat stehen damit in Bezügen zum volkskundlichen, zum juristischen und zum religiösen Heimatbegriff. Und in Karl Gutzkows Zeitschrift Unterhaltungen am häuslichen Herd erscheint 1852 die erste Fassung von Berthold Auerbachs Dorfge-

50 Königswinter 1864, S. 735.

51 Anonym: Sie gehen nach Amerika, 1864, S. 86.

52 Anonym: Charakterköpfe, 1864, S. 96. 
schichte Der Viereckig oder die amerikanische Kiste (vgl. II.2.2.2), einer literarischen Auseinandersetzung mit Heimat unter dem Vorzeichen von Auswanderung. Aber auch ein volkskundlicher Beitrag über Bräuche der „Heimat“"53 oder ein Gedicht, das die „wahre Heimat“ im Himmel findet, sind im selben Jahrgang enthalten. ${ }^{54}$ Die Liste dieser Texte und Kontexte ließe sich erweitern..$^{55}$ Es wird deutlich, dass die semantische Vieldeutigkeit von Heimat nicht allein eine Sache der Literatur ist, sondern literarische Heimatbegriffe ihrerseits im Kontext ganz unterschiedlicher Konnotationen des Begriffs stehen.

Das Interesse an den diskursiven Verflechtungen der Rede von Heimat und die Bündelung der Quellen unter den Aspekten Religion, Recht und Wissenschaft bringen es mit sich, dass literaturwissenschaftlich übliche Epocheneinteilungen nur eine untergeordnete Orientierungsgröße für diese Studie bilden. Auch wenn im Kapitel zur Religion ein Schwerpunkt auf Texten der Romantiker, in dem zum Recht ein Schwerpunkt auf Texten der Realisten und in dem zur Wissenschaft ein Schwerpunkt auf Texten von Realismus, Naturalismus und sogenannter Heimatkunst liegt, ergeben die Kapitel im Gegenzug nur unvollständige Aussagen über ein ,romantisches', ,realistisches‘ oder ,naturalistisches‘ Heimatverständnis.

Die Verflechtungen sind beispielsweise in Bezug auf die Frage nach religiöser Heimat schon allein im Feld der Literatur stärker, als das eine Systematik der Epochen gestattet: Jung-Stillings mystisch-spiritistische Texte stehen Novalis, Kerner und Schubart in Bezug auf Heimat näher als die E.T.A. Hoffmanns oder Eichendorffs. Eichendorff weist in Bezug auf Heimat in einigen Aspekten wiederum stärkere Parallelen zu Droste-Hülshoffs ,biedermeierlichen` Texten auf als

53 Anonym: Deutsche Sitten in Böhmen, 1852, S. 523.

54 „Des Herzens wahre Heimat / Suchst du dir die Wärme des Lebens, wählst du zuletzt doch nur den besten Weg, wenn du dem Lichte folgst.“ Anonym: Des Herzens wahre Heimat, 1852, S. 512. 55 Ein drittes Beispiel ist Gustav Freytags und Julian Schmidts Zeitschrift Die Grenzboten. Hier erscheint 1862 Fritz Reuters Erzählung Ein Heimatloser in Mecklenburg, in der das Versagen des Staates gegenüber einem heimatlos Gewordenen dargestellt wird (vgl. II.2.2.1), genauso wie verschiedene fachliche und historische Abhandlungen zum Heimatrecht, aber auch zur pädagogischen Heimatkunde und zur literaturgeschichtlichen Heimatkunst. Fritz Reuters Erzählung erschien im 21. Jahrgang von 1862, im selben Jahrgang findet sich der Begriff des rechtlich Heimatlosen auch im Beitrag „Die Milizen und Lanzknechte des griechischen Alterthums“. Und mit vorherigen Jahrgängen lässt sich die Liste der teils konvergierenden, teils abweichenden Heimatsemantiken erweitern: In einer Darstellung der Zustände in Rom im Beitrag „Die päpstliche Armee“ im 18. Jg. von 1859, in einem über „Die Rückschrittspartei und die Grundeigentumsfrage“ im 17. Jg. von 1858 oder über „Die Armenpflege im alten Rom“ im 16. Jg. von 1857 spielt die juristische Bedeutung von Heimat ebenfalls eine Rolle. Insbesondere in den 1890er Jahren, der Charakter der Zeitschrift hat sich inzwischen gewandelt, wird das Heimatrecht viel in der Zeitschrift diskutiert, genauso wie die Heimatkunde. In den Jahren zwischen 1900 und 1910 wird ,Heimatkunst‘ und ,Heimatliteratur‘ immer wieder zum Thema. 
beispielsweise zu Brentano, der wiederum in die Nähe von Hölderlin rückt. Und auch Ernst Moritz Arndts religiöse Heimatentwürfe gehören zum Bild der Zeit. Vor diesem Hintergrund sind einige hartnäckige Missverständnisse der literaturwissenschaftlichen Forschung geradezurücken. Diese betreffen erstens die Stellung der Romantik für die Herausbildung der modernen Heimatsemantik und zweitens die Trennung von sogenannter Hoch- und Trivialliteratur in Bezug auf Fragen des Heimatdiskurses. ${ }^{56}$

Zunächst ist es verkürzend, von einer Geburt des modernen Heimatverständnisses in der Epoche der Romantik zu sprechen. ${ }^{57}$ Denn die Transformationen der Heimatsemantik setzten in den 1770er Jahren, also schon deutlich früher ein. An ihr arbeiten Autoren der Empfindsamkeit wie Karl Philipp Moritz oder Johann Heinrich Voß, und parallel zu den Frühromantikern sind es auch Autoren wie Johann Heinrich Jung-Stilling oder Friedrich Hölderlin, die literarische Heimatsemantiken entwickeln. Außerdem werden die Transformationen des Heimatbegriffs im Anschluss an Hermann Bausingers einflussreiche Darstellung immer wieder als radikaler Bruch mit einer älteren, gänzlich nüchternen Heimatvorstellung gedacht, die gegen eine (dann oft der Romantik unterstellte) sentimentale eingetauscht worden sei. Immer wieder wird von einer mehr oder weniger plötzlichen Sentimentalisierung eines zuvor nüchternen Rechtsbegriffs ausgegangen. ${ }^{58}$ Wie zentral aber schon um 1800 die ältere religiöse Bedeutung für die Ausbildung einer neuen Heimatsemantik war, wird dabei meist übersehen. Dabei ist es die alte Emphase des religiösen Begriffs, die durch die Literatur um 1800 auf weltliche Gegenstände transponiert wird. Solche weltlichen Gegenstände sind meist Ideen oder Orte, die ungreifbar bleiben. Diese Orte liegen teils in der Ferne, teils im eigenen Inneren, in beiden Bedeutungen etwa bei Justinus Kerner. ${ }^{59}$ Heimat ist bei Ludwig Tieck und Wilhelm Heinrich Wackenroder in der

56 Der folgende Abschnitt zur Stellung der Romantik enthält Überschneidungen zu Oesterhelt 2020, S. 23-27.

57 „Die historisch erste Bewegung, die das Thema Heimat in seiner heutigen Bedeutung hervorgebracht hat, war die deutsche Romantik [...].“ Moosmann 1980, S. 46.

58 Vgl. Bausinger 1984. Walter Jens behauptete, dass Heimat „bis zur Mitte des neunzehnten Jahrhunderts ein nüchternes Wort“ gewesen sei: „von Traulichkeit, Poesie und sentimentalem Glanz keine Rede“. Jens 1985, S. 14.

59 „Ich weiß ein Tor, das mir das herbe Leben süßt,/ Das ist das Augenlid, das meine Augen schließt./ Quält mich die Welt und läßt der Mensch mir keine Ruh',/ Schließ ich dies Tor und geh der innern Heimat zu.“ Justinus Kerner: Das Augenlid (1861), in: Kerner 1981, S. 46. Der Wanderer trägt bei Kerner Heimat im Herzen und deswegen kann er sie auch in der Fremde haben: „So wird ihm zur Heimat/ Das ferneste Land.“ Justinus Kerner: Wanderlied (1809/12), in: Kerner 1981, S. 5-6. 
eigenen Seele $\mathrm{zu}$ finden ${ }^{60}$ und bei Bettina von Arnim in der Liebe. ${ }^{61}$ Bei Friedrich Schlegel kann die Poesie Heimat geben ${ }^{62}$ und bei E.T.A. Hoffmann ist Heimat mit der Musik verbunden. ${ }^{63}$

Es ist falsch, wenn behauptet wird, erstmals in der Romantik hätte Heimat sich als ein „emotional aufgeladener Begriff“ herausgebildet, „der mit Natur, Landschaft, kleinstädtischem Leben und Dorfidylle zusammenhängt und ganz bestimmte Gefühle und Stimmungen assoziieren läßt: Vertrautheit, Überschaubarkeit, Verwurzelung, Ruhe und Abgesichertheit“. ${ }^{64}$ Die literarische Semantik von Heimat, wie sie neben den Romantikern auch Jung-Stilling oder Hölderlin prägen, zeichnet keine sentimentalen Dorfidyllen. ${ }^{65}$ Es ist vielmehr konstitutiv für diese literarischen Heimaten, dass sie nie erreicht werden können. Heimat wird nicht primär als sentimental-idyllisierendes, sehr wohl aber als emphatisches Konzept entfaltet, und die Autoren schöpfen dabei aus der traditionellen religiösen Semantik des Begriffs. Das Novum ist bei allen diesen Autoren die semantische Überlagerung eines irdischen und eines transzendenten Heimatbegriffs. Heimat ist nicht nur ein Ort, sondern auch ein Gefühl oder eine Idee, und sie kann wahlweise auch im eigenen Innern, in der Kunst oder in der Liebe gefunden werden. Der romantische Wanderer lässt sich in diesem Sinn als „moderne, sä-

60 „Welcher aber in seiner eigenen Seele die Heimath aller der Erkenntnisse und Kräfte, worin sonst viele sich theilen, findet, und wessen Geist, mit gleichem Eifer und Glücke, durch Schlüsse der Vernunft Wahrheiten ausrechnet, und Einbildungen seines innern Sinnes durch Mühsamkeit der Hand in sichtbare Darstellungen hervordrängt: - ein solcher muß der ganzen Welt Erstaunen und Bewunderung abnöthigen.“ Tieck/Wackenroder 1797, S. 85.

$\mathbf{6 1}$ „Die Nacht ift ganz ftille, ich bin ganz allein, die Ferne ift fo weit, fie ift ohne Ende; nur da wo ein Liebender wohnt, da ift eine Heimath und keine Ferne; wenn Du nun liebteft, fo wüßt’ ich, wo die Ferne aufhört.“ Arnim 1835, S. 15.

62 „Es ist ein schönes Verdienst der modernen Poesie, daß so vieles Gute und Große, was in den Verfassungen, der Gesellschaft, der Schulweisheit verkannt, verdrängt und verscheucht worden war, bei ihr bald Schutz und Zuflucht, bald Pflege und eine Heimath fand." Friedrich Schlegel in Über das Studium der Griechischen Poesie von 1795-1797; Schlegel 1988, S. 68.

63 Die Musik könne das „wunderbare Streben“, „unsere überirdische Heimat“ zu erkennen, zum Ausdruck bringen. E.T.A. Hoffmann: Alte und neue Kirchenmusik, in: Hoffmann 1993, S. 503-531, hier S. 526.

64 Moosmann 1980, S. 46. Diese Auffassung wird in der Forschung mehrfach mit direktem Bezug auf Moosmann übernommen, vgl. Neumeyer 1994, S. 16.

65 Das ist wohl der Grund, warum Friedrich Sengle den Beginn des modernen Heimatbegriffs auf die Biedermeierzeit datiert: „Tatsache ist aber, daß erst die Biedermeierzeit, in der Fortsetzung von Bemühungen, an denen Aufklärung und Romantik gleichermaßen Anteil hatten, den modernen Heimatbegriff und damit eine wirksame Kraft gegen die Allmacht abstrakter Großorganisation geschaffen hat." Sengle 1971, S. 51. Sengle versteht unter dem modernen Heimatbegriff anscheinend seinen regionalen Bezug. 
kulare Version des christlichen Pilgers verstehen. Nur setzt die Romantik Kunst und Poesie an die Stelle der traditionellen Religion, Künstler und Dichter sind die neuen Pilger“. ${ }^{66}$ Nicht der stubenhockende Philister, sondern der von Fernweh geplagte Wanderer ist, wie Susanne Scharnowski in Bezug auf die Heimatfrage klargemacht hat, das Leitbild der Romantik. „Darum, Freunde! will ich reisen;/ Weiset Straße mir und Ziel!/ In der Heimat stillen Kreisen/ Schwärmt das Herz doch allzuviel.“67 Je nach Standpunkt gilt immer nur dem räumlich und zeitlich entfernten Ort die Sehnsucht: der Ferne oder eben der Heimat, wenn man nicht dort ist. ${ }^{68}$ Gleichwohl gibt es zu diesem historischen Zeitpunkt durchaus auch schon sentimentale und auf das Dorfidyll der Kindheit bezogene Heimatvorstellungen, etwa bei empfindsamen Autoren wie Johann Gaudenz von Salis-Seewis. Solche - zu dieser Zeit noch singulären - sentimentalen Heimatentwürfe sind also tatsächlich schon vorhanden und es ist umso bemerkenswerter, dass die Frühromantiker daran nicht anknüpfen.

Eine weitere oft falsch beantwortete Frage ist die Verbindung von romantischen Heimatkonzepten mit der Herausbildung von Nationaldiskursen. Teils wird unterstellt, dass die Romantik die unheilige Allianz von Heimat und Nationalismus begründete, teils wird argumentiert, dass es diese Verbindung gar nicht gebe: „In diesem ganz und gar immateriellen Universum der Romantik ist Heimat in der Tat nichts als eine Idee, eine Chiffre für ein mit ästhetisch-religiösen Sehnsüchten und Erlösungshoffnungen durchsetztes ,Nicht-Hier' und ,Nicht-Jetzt'. Diese romantische Heimat bezieht sich weder auf Nation und Volk oder auf Land und Leute noch gar auf Blut und Boden. “69 Tatsächlich findet sich in politischen Texten der Romantik der Begriff der Heimat sogar eher im abwertenden Sinn: Johann Gottlieb Fichte befindet in den Reden an die deutsche Nation (1808), dass bei der Herausbildung des deutschen Volkes „die Veränderung der Heimath ganz unbedeutend“ sei: „Der Mensch wird leicht unter jedem Himmelsstriche einheimisch“ und die „Volkseigenthümlichkeit“ sei „weit entfernt durch den Wohnort sehr verändert zu werden“ “ ${ }^{70}$ Und Friedrich Ludwig Jahn schimpft auf „kindisches

66 Scharnowski: Heimat, 2019, S. 26. Susanne Scharnowski argumentiert insgesamt für eine differenziertere Beurteilung des romantischen Heimatbegriffs, der ich mich anschließe. Allerdings würde ich nicht in der Weise argumentieren, dass es wahrscheinlich immer schon einen emotional besetzten Heimatbegriff gegeben habe, sondern auf der historischen Herausbildung einer spezifisch modernen Semantik von Heimat bestehen, die sich aber eben vor der Romantik, um 1770, entwickelte.

67 Ludwig Uhland: Reisen (1834), in: Uhland 1980, S. 45.

68 Vgl. Scharnowski: Heimat, 2019, S. 26.

69 Scharnowski: Heimat, 2019, S. 33.

70 Fichte 1846, S. 313. Für Fichte ist die Sprache der prägende Faktor für die Herausbildung eines Volkes. 
Zurückverlangen nach der Erdscholle“ und möchte die Herausbildung eines Nationalbewusstseins nicht über die Liebe zur Heimat, sondern über die „Sehnsucht nach dem Vaterlande“"71 erreichen:

[W]er nichts Tieferes kennt als die Viehschwemme, und den Ziehbrunnen, nichts Höheres ahnt, als den Wetterhahn auf dem Glockenthurm - bleibt ein Kleinstädter. Wer endlich schon darum allein Menschen ausschließlichen Werth beilegt, weil sie mit gleichem Wasser getauft, mit dem nämlichen Stocke gezüchtigt, denselben Koth durchtreten, oder von Jugend auf gleiche Klöße, Fische und Würste mit Salat gegessen, dieselbe Art Schinken und Jütochsen verspeiset, oder Pumpernickel, Spickgänse und Mohnstrizel verzehrt; und deshalb nicht mehr verlangt, sondern geradezu fordert, daß jedermann echt kloßicht, wursticht, fischicht, salaticht, schinkicht, jütochsicht, pumpernicklicht, spickgänsicht und mohnstritzlicht bleiben soll - liegt am schweren Gebrechen der Landsmannschaftsucht darnieder. Wer indessen von der Verkehrtheit ergriffen war, seine Hufe Land für ein Königreich, seine Erdscholle für ein Volksgebiet anzusehen, und die andern Mitvölker und Invölker des Gesammtvolks nebenbuhlerisch anzufeinden, damit nur statt eines Gemeinwesens, das Unwesen von Schöppenstädt, Schilde u. s. w. bestehe:- hatte Theil an dem Unsinn der Völkleinerei, in welcher Deutschland unterging. ${ }^{72}$

Jahn wendet sich hier gegen eine - im weiteren Textverlauf auch direkt mit dem Begriff der Heimat verbundene - „Landsmannschaftsucht“, die politisches Denken im größeren Maßstab gerade verhindere; die philiströse und bornierte Heimat ist demnach geradezu ein Gegenkonzept zum Ideal der geeinten Nation (vgl. I.2.1).

Trotz solcher Beispiele wäre es falsch, eine Verbindung von Heimat- und Nationaldiskursen historisch erst nach der Romantik anzusetzen. Schon in den literarisch-politischen Texten des Göttinger Hainbundes beginnt eine Ausdifferenzierung von Vaterland und Heimat, in der die Vaterlandsliebe einer abstrakteren, politischen Idee zugeordnet wird, die Heimatliebe sich dagegen mit dem Leiblichen und Vegetativen, dem Passiven und Gefühlvollen zu verknüpfen beginnt. Besonders an Ernst Moritz Arndts in der Zeit von Romantik und Vormärz geschriebenen Texten zeigt sich, wie Heimat als vermeintlich unpolitische Bezugsgröße dabei auf intrikate Weise zum Politikum wird. Gerade indem der Begriff entpolitisiert wird, hält er Einzug in den politischen Diskurs (vgl. I.2.1). „Nationale Ideen“ ${ }^{73}$ kamen nicht, wie es Helmut Koopmann darstellt, erst nach der Romantik

71 Alle Zitate Jahn 1810, S. 271.

72 Jahn 1810, S. $118-119$.

73 Koopmann 2005, S. 41. Koopmanns Aufsatz zu Heimat, Fremde und Exil im 19. Jahrhundert enthält noch andere Fehlurteile. Dass es für Novalis Heimat noch „als etwas Erreichbares“ gegeben habe, während nach Novalis „wenige Jahrzehnte“ genügt hätten, „um das Bewußtsein dafür zu schärfen, daß „Heimat‘ etwas ein für allemal Verlorenes war“ (alle Zitate Koopmann 
auf, sondern vor ihr und in ihr, und das teilweise eben auch als Teil des Heimatdiskurses. Und die romantische Vorstellung, Heimat im eigenen Innern suchen zu können, in der Vorstellungs- und Dichtkraft, im Gemüt, ist zentraler Bestandteil der Heimatvorstellungen des weiteren 19. Jahrhunderts, die sich zweifelsohne mit den nationalistischen Heimatdiskursen verbanden, die gerade im deutschen Gemüt den eigentlichen Sitz der Heimatliebe entdecken wollten, wie auch etwa schon in Hegels Vorlesungen über die Geschichte der Philosophie von 1805/06 (vgl. II.1.3.1). Die Behauptung ist verkürzend, dass sich erst die „Ideologen des 20. Jahrhunderts die romantische Sehnsucht nach einem Zuhause und die Angst vor der Fremde“ zunutze und aus Heimat „Gefühlskitsch“ gemacht hätten. ${ }^{74}$ Die romantischen Heimaten spielten schon im ganzen 19. Jahrhundert auch eine wichtige ideologische Rolle und gerade die politische Funktionalisierung einer vermeintlich unpolitischen Heimat ist historisch schon vor und in der Zeit der Romantik zu finden. ${ }^{75}$

Mit der in der Literaturwissenschaft teils bis heute vorgenommenen Trennung eines unantastbaren romantischen und hochliterarischen Heimatbegriffs und einer späteren trivialen Literatur, die für Heimatkitsch steht, verbindet sich außerdem ein anderes grundsätzliches Problem literaturwissenschaftlicher Ansätze: eine wertende Trennung von Hoch- und Populärliteratur. Walter Jens etwa unterschied noch ein gutes, kosmopolitisches Heimatverständnis der Unterdrückten von einem schlechten, philiströsen und ideologischen Heimatverständnis der Durchschnittlichen: „Nur die Poesie der Ausfahrer, Exilierten und Vertriebenen kann adäquat beschreiben, was Heimat ist - nicht die Dichtung der Nesthocker, die ihr heimeliges Glück im Winkel besingen“. Zum Kreis der „Autoren von Rang“, ${ }^{76}$ die adäquat über Heimat sprechen, zählt Jens Hölderlin, Heine, Brecht und Fontane, während Wilhelm Heinrich Riehl ihm antikosmopolitischer „Heimatideologe“77 ist. Die ,schlechte“, nämlich sentimentale, antikosmopolitische und zugleich ideologische Heimatliteratur wird mit Autoren wie „den Riehls und Roseggern“, den „Gartenlauben-Autoren und Verfassern von Heimatdichtungen um 1900“78 verbunden. Jens übersieht dabei, dass beispielweise der von ihm positiv herausgehobene Theodor Fontane in der Gartenlaube

2005, S. 41), ist eine Aussage, die weder in Bezug auf Novalis noch in Bezug auf das sehr viel ältere (religiöse) Bewusstsein der Unerreichbarkeit von Heimat haltbar ist.

74 Beide Zitate Koopmann 2005, S. 41.

75 Zur These der politischen Funktionalisierung einer vermeintlich unpolitischen Heimat vgl. auch schon Bausinger 1986, S. 97.

76 Beide Zitate Jens 1985, S. 17.

77 Jens 1985, S. 15.

78 Jens 1985, S. 17. 
veröffentlichte und Heimat um 1900 auch ein wichtiger Begriff für Autoren wie Georg Trakl, Rainer Maria Rilke, Albert Ehrenstein, Yvann Goll oder Georg Heym war, die der Klassischen Moderne zugeordnet werden. ${ }^{79}$ Die Scheidung in ein richtiges und ein falsches Sprechen über Heimat ignoriert die vielfältigen Überschneidungen der Diskurse. Fontane war ein Riehl-Leser und ohne diese Lektüren wären die Wanderungen durch die Mark Brandenburg, aus denen Jens wohlwollend zitiert, nicht geschrieben worden. Ein Autor wie Wilhelm Raabe, dessen Romane sehr subtile Heimatreflexionen enthalten (und der in dieser Studie leider nicht so ausführlich zur Sprache kommt, wie es angemessen wäre, vgl. I.2.1), müsste nach Jens’ Kategorien zum ,Nesthocker` erklärt werden. Und insgesamt sind es eben nicht nur ,Autoren von Rang', sondern auch eindeutig als Unterhaltungsautoren klassifizierte und oft dezidiert abfällig dem Heimatroman-Genre zugeordnete Schriftsteller und Schriftstellerinnen, deren Texte bei näherem Hinsehen Heimatbilder entwerfen, die Herkunftsort und Dorfgemeinschaft in düsteres Licht rücken und mehr über gestörte Bindungen als über heimelige Zufluchtsorte sprechen, wie z.B. Wilhelmine von Hillerns Roman Die Geier-Wally (1873). ${ }^{80}$ Wenn sich Hermann Bausinger (kein Literaturwissenschaftler) gerade auf Wilhelm Ganzhorns populäres Lied Im schönsten Wiesengrunde ist meiner Heimat Haus bezieht, um das sentimentalisierende Heimatbild des 19. Jahrhunderts als „Kompensationsraum“ und „Besänftigungslandschaft“ zu decouvrieren, muss man fragen, ob sich nicht auch an hochliterarischen Texten wie etwa frühromantischer Lyrik solche Thesen vertreten ließen. ${ }^{81}$

Diese Studie versucht aus den genannten Gründen, Wertungen zu vermeiden, die sich mit den Kategorien von Hoch- und Trivialliteratur verbinden, dafür aber die impliziten Leitbilder und Wertmaßstäbe der Texte sichtbar zu machen. Die Geschichte der Heimat ist nicht immer als Ideologiegeschichte zu schreiben, aber sie hat Teil daran. Und diesen Teil können Hölderlins Heimatentwürfe genauso wie diejenigen Roseggers bilden.

Eine explizite Ideologiekritik von Heimat ist im 19. Jahrhundert so gut wie nicht zu finden; vielmehr sind es literarische Texte, die diese Funktion teilweise übernehmen. Eine kurze Stelle findet sich allerdings in Karl Marx’ Deutscher

79 Gedichte mit Heimat als zentralem Begriff schreiben Georg Trakl (In der Heimat, Abendland), Rainer Maria Rilke (Das Heimatlied), Albert Ehrenstein (Heimkehr), Yvan Goll (Heimat) und Georg Heym (Die Heimat der Toten). Dass viele gewöhnlich der Moderne zugerechnete Autoren wie Heinrich und Thomas Mann, René Schickele oder Rilke zum Phänomen des Heimat-Hypes um 1900 gehören, zeigt Kramer 2006.

80 Vgl. Scharnowski: Geier-Wally, 2019. Der Roman wurde vor allem auch durch seine Filmadaptionen in die seichte Heimatecke gestellt, wie der Aufsatz ausführt.

81 Vgl. Bausinger 1986, S. 96. 
Ideologie. Im Abschnitt Sankt Max, der eine polemische Auseinandersetzung mit der Philosophie Max Stirners darstellt, kommentiert Marx kursiv gesetzte Zitate von Stirner:

„Hat ja doch der Himmel keinen anderen Sinn, als den, daß er die eigentliche Heimath des Menschen ist“ - wo er im Gegentheil die vorgestellte Uneigentlichkeit der eigentlichen Heimath zum Sinn hat; / „worin ihn Nichts Fremdes mehr bestimmt“ - d.h. worin ihn das Eigne als Fremdes bestimmt, \& wie die nun in Gang gebrachte Leier weiter heißt. ${ }^{82}$

Marx kritisiert hier die stirnersche Vorstellung einer himmlischen Heimat, in der es keine Fremdbestimmung mehr gebe. Die eigentliche Heimat, so kann man Marx verstehen, liegt im Diesseits, nicht im Jenseits. Und während es darum gehen muss, diese irdische Heimat zu einem selbstbestimmten, unentfremdeten Lebenszusammenhang zu machen, will Stirner genau dieses ganz reale und irdische Anliegen ins ,Uneigentliche' ziehen. Damit bewertet Marx religiöse Auffassungen von Heimat insgesamt als Ideologie, nämlich als Entstellung der Realität. ${ }^{83}$ Heimat kommt als Begriff bei Marx sonst so gut wie nicht vor, er benutzt eher - im selben Sinn wie oben - die Metapher des Zu-Hause-Seins. Über den Arbeiter schreibt er: „Zu Hause ist er, wenn er nicht arbeitet, und wenn er arbeitet ist er nicht zu Haus." Erst ein selbstverwirklichter Mensch, der in seiner Arbeit nicht entfremdet ist, könne dieses Zu-Hause finden. ${ }^{84}$

Heimat ist ein Schlüsselbegriff des 19. Jahrhunderts, an den sich auf unterschiedliche Weise verschiedene Ideologien anlagerten..$^{85}$ Diese Studie wird vor allem im Kapitel zur Heimatkunde (vgl. II.3.1) zeigen, wie das pädagogische Konzept und in diesem Kontext auch der Begriff der Heimat im Lauf des 19. Jahrhunderts einem so radikalen Wandel unterlag, dass man geradezu von einer Umkehrung der Bedeutung von Heimat sprechen kann. Während Heimat am Jahrhundertanfang für einen Raum jenseits nationaler Grenzen stehen kann (z. B. im deutsch-französischen Rheingebiet) und für einen Raum, der durch unmittelbare Anschauung erfahrbar und insofern gerade frei von größeren Ideen oder Theorien ist, ist Heimat ab dem letzten Jahrhundertdrittel zum Symptom ihrer

82 Marx 2017, S. 218.

83 So etwa Herbert Schnädelbachs Aufsatz Was ist Ideologie?, vgl. Schnädelbach 1969.

84 So Klaus Weber in seinem Lexikonartikel zu ,Heimat‘ im Historisch-kritischen Wörterbuch des Marxismus, vgl. Weber 2004, Sp. 46, Zitat nach Weber.

85 Horst Dieter Schlossers Buch Die Macht der Worte. Ideologien und Sprache im 19. Jahrhundert entwickelt die ideologische Funktionalisierung zentraler Schlüsselbegriffe im 19. Jahrhundert etwa an den Begriffen Freiheit, Einheit und der Trias Volk - Vaterland - Nation, vgl. Schlosser 2016. 
gänzlichen Ideologisierung mit dem Zweck nationaler Identitätsstiftung geworden. Sie wird zum nationalen Religionsersatz der Deutschen:

[G]ebt dem deutschen Volk ein Herz voll Liebe zur Scholle. Ohne Religion und Gemütstiefe ist der Deutsche nur ein halber Mensch. Ist es nicht psychologisch bezeichnend, daß nur unsere Sprache das Wort „Gemüt“ prägen mußte, während es Franzosen und Engländer nicht besitzen? Die Heimatliebe, die uns Deutschen unsere seelenvollsten Volkslieder schenkte, sei der voll- und wohlklingende Akkord im deutschen Gemütsleben. ${ }^{86}$

Das Heimatbuch der Schule als „eine weltlich[e], eine nationale Bibel, die jeden Deutschen auf seinem Lebenswege begleite“ ${ }^{87}$ zeichnet dabei Bilder von Heimat, die mit ihren Schäferidyllen und ihrem ruralen Dorfleben nichts mit den Lebensrealitäten der in Mietskasernen lebenden Schüler der Großstädte zu tun haben. Heimat ist hier zur Ersatzwirklichkeit geworden, und in diesem Sinn ist sie Komplementärideologie, eine die Realität verleugnende Verheißung, die in manipulativer Absicht eingesetzt wird. ${ }^{88}$

Neben den in dieser Arbeit im Zentrum stehenden unterrichtspädagogischen Programmatiken und der fiktionalen Literatur, die sie heranziehen, sind Kinderbücher ein weiteres Beispiel für wirkungsvolle erzieherische Maßnahmen in Sachen Heimat. Von Friedrich Gülls erfolgreichem Kinderbuch Kinderheimat von 1836, in dessen Vorwort Güll das Kind als dem „Reiche der Poesie“ entstammend versteht und den Zweck des Buches als „die Bildung des Gemüths als Träger der edelsten Humanität “89 bezeichnet, ist es ein weiter Weg bis zu Waldemar Bonsels Biene Maja von 1912, in der es im Kern um die Entwicklung Majas hin zu „Todesbereitschaft“ und „,beseligte[m] Opferwille[n]“90 für Heimat und Volk geht (vgl. I.2.2). ${ }^{91}$

\subsection{Forschung, Begriffe und Methoden}

„Heimat' ist sehr beliebt für Publikationstitel aller Art. Einen Überblick über Literatur zum Thema zu gewinnen, ist schon deswegen ein undankbares Unterfangen, weil Heimat für Tausende von Titeln vorrangig die Funktion eines stim-

86 Mollberg 1916, S. 6.

87 Weber 1872, S. $110-111$.

88 Zur Kategorie der Komplementärideologie vgl. Lenk 1994.

89 Güll 1978, o.S.

90 Bonsels 1949, S. 150.

91 Für die Kinder- und Jugendbuchforschung zum Thema Heimat vgl. das Themenheft der Zeitschrift kjl von 2008 und dort exemplarisch den Beitrag von Rutschmann 2008. 
mungsvollen Füllsels oder eines ,eye catchers ${ }^{6}$ hat. ${ }^{92}$ Zudem sind die Übergänge zwischen Fachliteratur und populärer Sachbuchliteratur gerade bei diesem Thema oft fließend und die Anzahl an Monographien, die sich irgendwo zwischen Forschung, Essay und Meinungsbekundung bewegen, ist groß. ${ }^{93}$ Auch die Menge wissenschaftlicher Publikationen im engeren Sinn ist inzwischen schier unüberschaubar. Die seit den 1970er Jahren herausgegebenen Sammelbände und Sonderzeitschriftennummern zum Thema überschreiten das halbe Hundert, ${ }^{94}$ die Zahl einzelner Aufsätze hat allein in der deutschsprachigen Literaturwissenschaft die Zweitausendermarke längst geknackt, ${ }^{95}$ aber das Thema wird genauso in Kulturanthropologie und Vergleichender Kulturwissenschaft, in Soziologie und Geschichtswissenschaft, in Psychologie und Philosophie erforscht.

Statt eines erschöpfenden Überblicks über die unterschiedlichen fachwissenschaftlichen Forschungen (sie werden sukzessiv bezogen auf den jeweiligen thematischen Fokus behandelt) sollen deswegen an dieser Stelle einige basale methodische Grundannahmen diskutiert werden, die sie auszeichnen. Dazu werden hier alle ab den 1970er Jahren erschienenen Monographien zu ,Heimat‘ in

92 Vgl. exemplarisch Stefanie Stahls Das Kind in dir muss Heimat finden. Der Schlüssel zur Lösung (fast) aller Probleme von 2015, das inzwischen in der 25. Auflage erschienen ist und in mehr als zwanzig Sprachen übersetzt wurde; laut Bestsellerliste des Börsenblatts liegt das Buch auf Platz 1 der meistverkauften Bücher im Bereich Ratgeber im Jahr 2016 sowie auf Platz 1 der Jahresbestseller in den Jahren 2017, 2018 und 2019 bei Buchreport. Seit 2016 befindet es sich ununterbrochen in der Spiegel-Bestsellerliste im Bereich Sachbuch, vgl. Stahl 2015.

93 Vgl. exemplarisch Schmidt 1994, Schlink 2000, Türcke 2006, Schmitt-Roschmann 2010, Egger 2014, Klare 2016, Schüle 2017, Schreiber 2017.

94 Vgl. interdisziplinär, aber ohne Anspruch auf Vollständigkeit: Bausinger/Köstlin 1979, Moosmann 1980, Riedel 1981, Greverus/Schilling 1982, Weigelt/Altmann 1984, Bausinger/Wehling 1984, Führ 1985, Bienek 1985, Kelter 1986, Pott 1986, Weigelt 1986, Seliger 1987, Hasse 1987, Blumenwitz 1987, Polheim 1989, Hacker/Lippert 1989, Bundeszentrale für politische Bildung 1990, Klueting 1991, Müller-Funk 1992, Görner 1992, Riedl 1995, Schilling 1995, Belschner 1995, Blumenwitz 1995, Belschner/Grubitzsch/Leszczynski/Müller-Doohm 1995, Hermand/Steakley 1996, Biehl 1997, Ecker 1997, Knoch 2001, Liptay/Marschall/Solbach 2005, Umbach/Hüppauf 2005, Heinze/Quadflieg/Bühring 2006, Hofmeister/Bauerochse 2006, Gebhard/Geisler/Schröter 2007, Hanika/Trunk 2007, Beghin/Bernard/Eggers 2009, Seifert 2010, Beer 2010, Eigler 2012, Klose/ Lindner/Seifert 2012, Eigler/Kugele 2012, Klose 2013, Eichmanns/Franke 2013, Fischer 2013, Bauer/Gremler/Penke 2014, Bescansa/Nagelschmidt 2014, Costadura/Ries 2016, Costadura/Ries/ Wiesenfeld 2019, Brinkmann/Hammann 2019, Bland/Smale/Weiss-Sussex 2019, Barboza/KrugRichter/Ruby 2019, Nassehi/Felixberger 2019, Michael 2019, Ramb/Zaborowski 2019, Biemann/ Cohen/Wobick-Segev 2019, Seifert 2000, Neuhaus/Arendt 2020, Bescansa/Saalbach/Talavera/ Iztueta 2020, Althammer/Oesterhelt 2021.

95 Allein für den Zeitraum 1985-2010 verzeichnet BDSL online, die umfassendste Bibliographie literaturwissenschaftlicher (teils auch sprachwissenschaftlicher) Publikationen, über 1.800 Einträge. 
den Blick genommen, sofern sie historisch und systematisch breit angelegt sind; ergänzend werden einige weitere wichtige oder repräsentative Arbeiten exemplarisch herangezogen. ${ }^{96}$ Mit dieser methodischen Perspektive lassen sich zwei basale Textgruppen bilden: wissenschaftliche Texte, die von einem operationalisierbaren, methodisch belastbaren Heimatbegriff ausgehen, und solche, die das nicht tun.

Ina-Maria Greverus' volkskundliche Habilitationsschrift Der territoriale Mensch. Ein literaturanthropologischer Versuch zum Heimatphänomen von 1972 unternimmt einen umfassenden Klärungsversuch. Auf der Grundlage einer breiten Materialbasis, die sich über unterschiedliche Jahrhunderte hinweg auf hochund populärkulturelle, disziplinäre und alltagspragmatische Diskurse und Praktiken erstreckt, erforscht die Arbeit das ,Phänomen“ Heimat in seiner ganzen kulturhistorischen Breite. Trotz der historisch differenzierten Quellenbehandlung verfolgt Greverus' Arbeit allerdings keine historische These. Vielmehr geht es ihr um den Nachweis einer anthropologischen Konstante. Ihre Prämisse ist, dass das ,Heimatphänomen“ in der affektiven Bezogenheit des Menschen auf bestimmte Orte und Räume besteht und diese menschliche ,Territorialität‘ als überhistorisch zu betrachten sei. Greverus spricht von einer „Grundtatsache des konkreten Raumes Heimat als Voraussetzung der sozialen und kulturellen Identitätsgewinnung “ und wendet sich damit gegen frühere soziologische Positionen, die Heimat primär als „zwischenmenschliche[n] Zusammenhang“ verstehen. ${ }^{97}$ Heimat könne historisch und kulturell sehr unterschiedlich überformt, auch ideologisiert und instrumentalisiert werden: „Die Tatsache Heimat wurde zur Idee Heimat und konnte dadurch zur Ideologie Heimat werden, mit der die Suche des Menschen

96 Mit Monographien, die sich engeren Zeitabschnitten oder speziellen Aspekten des Heimatdiskurses widmen, wird sich diese Studie sukzessive auseinandersetzen. Dies sind unter anderem Studien zur Heimatkunstbewegung um 1900 (vgl. Rossbacher 1975), zum Zusammenhang von Heimat und Nation in der Pfalz (vgl. Applegate 1990), zur Erzählprosa aus Tirol zwischen 1890 und der Gegenwart (vgl. Riedmann 1991), zum National- und Heimatdiskurs zwischen 1871 und 1918 (vgl. Confino 1997), zum Aspekt der Unheimlichkeit von Heimat (vgl. Strzelczyk 1999), zu ausgewählten Romanen und Filmen im Zeitraum von 1890 bis 1990 (vgl. Boa/Palfreyman 2000), zu Heimat im deutschen Film (vgl. Moltke 2005), zu Regionalismus und Moderne um 1900 (vgl. Kramer 2006), zur ,Kunstheimat‘ um 1800 (vgl. Schwarz 2007), zum medizinischen Heimwehdiskurs (vgl. Bunke 2009), zum Zusammenhang von Heimatkunst, Kolonialismus und Expeditionen zwischen 1880 und 1930 (vgl. Parr 2014), zum Zusammenhang von Heimat, Flucht und Vertreibung im 20. Jahrhundert (vgl. Eigler 2014) und zu postmodernen Heimatkonstruktionen (vgl. Geuen 2016).

97 Brepohl 1965, S. 43. Heimat ist für den Soziologen Wilhelm Brepohl „kein Raumbegriff“: „Sie ist ein [...] moralischer Begriff, ein Gefüge von Lebensregeln, die der Mensch durch Erziehung und Anpassung mitbekommt bzw. sich erarbeitet.“ Brepohl 1965, S. 46. Schon in den 1950er Jahren entwickelt Brepohl diese Position, vgl. Brepohl 1952. 
nach einem Satisfaktionsraum manipulierbar wurde. “98 Heimat bleibt nach Greverus von diesen Überformungen aber im Kern unberührt, eben eine ,Tatsache‘.

Sie argumentiert an anderer Stelle zwar, dass ,Heimat‘ immer nur ein „Untersuchungsgegenstand“ und nicht „Terminus Technicus“ sein könne. ${ }^{99}$ Der methodischen Unschärfe des Begriffs begegnet sie, indem sie ihn durch andere Begriffe ersetzt: Das „Phänomen einer menschlichen Bezogenheit auf ,Heimat““ und einer „menschliche[n] Suche nach umgrenzten und selbsterfahrenen Identitätsräumen"100 definiert Greverus deswegen als affektive Territorialbezogenheit. Obwohl Greverus Heimat also als analytischen Begriff verwirft, hält sie trotzdem am ,Heimatphänomen' genau in diesem analytischen Sinn der affektiven Territorialbezogenheit fest. Die spezifische Historizität ihrer Quellen ebnet Greverus durch diese anthropologische Grundannahme ein und so wird der Versuch eines Belegs ihrer These mithilfe der historischen Quellen leicht zu einer Tautologie. Weil Greverus definiert, was Heimat ist, kann sie dann auch Phänomene behandeln, in deren historischem Kontext der Begriff Heimat gar nicht auftaucht. ${ }^{101}$ Greverus' bei aller kulturhistorischen Reflektiertheit im Kern substantialistisches Heimatverständnis führt dazu, dass die Geschichte der Heimat von der Geschichte des Begriffs entkoppelt werden kann. Denn wenn es Heimat als affektiven Territorialbezug immer schon gab, dann wird der Ort, die Zeit und der diskursive Kontext, in dem der Begriff auftaucht, nebensächlich.

Heimat wurde in der Folge von Greverus' Studie und weiterer ihrer Arbeiten ${ }^{102}$ immer wieder und bis heute primär in seiner räumlichen Komponente und davon abgeleitet dann auch als „Ort personaler Identitätsfindung und sozio-politischer

98 Beide Zitate Greverus 1972, S. 303.

99 Greverus 1972, S. 48.

100 Beide Zitate Greverus 1972, S. 1.

101 Beispielsweise behandelt das Kapitel „Der Abschied der Braut“, in dem verschiedene europäische Hochzeitsrituale und -lieder auf ihre Territoriumsbezogenheit hin untersucht werden, den Abschied von dem ,Wertraum ' der Primärgruppe und den Übergang in den ,Wertraum ' der Sekundärgruppe als Teil des ,Heimatphänomens‘. „Der Begriff ,Heimat‘ als zusammenfassendes Symbol dieses Wertraums ist in den Liedern noch nicht zu finden, was die Erfassung der tatsächlich gemeinten Werte erleichtert“ (Greverus 1972, S. 87). Ein weiteres Beispiel: Dass es Heimatliebe schon bei Homer gebe, belegt Greverus mit der Übersetzung der Odyssee von Johann Heinrich Voß (vgl. Greverus 1972, S. 30), ohne zu sehen, dass eben erst Vossens Übersetzung mit ihrer ubiquitären Verwendung des Heimatbegriffs die Assoziation von Odyssee und Heimatliebe im deutschsprachigen Raum kulturgeschichtlich geschaffen hat (vgl. II.1.3.1). Der anthropologische Ansatz kann der historischen Differenzierung bestimmter begrifflich fixierter Semantiken keine besondere Rolle beimessen: Ob nun Vaterland, Heimat, Vaterhaus oder Daheimsein, für Greverus sind das alles Ausdrucksformen einer Universalie.

102 Vgl. Greverus 1979. 
Orientierung“103 definiert und als ein anthropologisch fundiertes Bedürfnis verstanden, das zu seinem Recht kommen müsse. So besteht der Philosoph Bernhard Waldenfels 1984 in einem Vortrag über Heimat in der Fremde in Abgrenzung von ideologischen Vereinnahmungen auf den „lebenserhaltenden Ansprüchen“, die sich ihm zufolge hinter der Vorstellung von Heimat verbergen. ${ }^{104}$ Auch wenn er nicht zu einer totalen, sondern nur partiellen ,Rückkehr` zu Heimat plädiert - als Mittelweg zwischen „Heimwelt“ und „Fremdwelt“ -, ${ }^{105}$ muss der Mensch nach seiner Ansicht dem für die eigene Gegenwart diagnostizierten „Heimatschwund“"106 entgegenwirken. Die ,Heimwelt‘, die in Waldenfels’ phänomenologischem Zugang für den gelebten Raum, die vertraute Welt, Bodenständigkeit, Geborgenheit und Verlässlichkeit steht, wird als menschliches Grundbedürfnis im Spannungsfeld zur ,Fremdwelt‘ verstanden.

Hier knüpft die philosophische Grundlagenarbeit von Karen Joisten, Philosophie der Heimat - Heimat der Philosophie aus dem Jahr 2003 an, deren geistige Bezugspunkte unter anderem Edmund Husserls Phänomenologie und Martin Heideggers Fundamentalontologie sind. Joistens Habilitationsschrift versteht Heimat als „Urphänomen [...], in dem Grundphänomene des menschlichen Lebens, das Sich-Orten, das Sich-Zeitigen und das Sich-Begegnen, zusammenlaufen“. Heimat sei „der Möglichkeit nach im Menschen als dessen unabtrennbares Korrelat von vornherein vorgezeichnet“. ${ }^{107}$ Der Philosophie spricht Joisten „die ureigenste Aufgabe zu, eine Philosophie der Heimat zu entwickeln“ - im Sinne einer systematischen Aufarbeitung eines philosophischen Grundproblems. ${ }^{108} \mathrm{Sie}$ geht so weit, Philosophie mit dem „Denken von Heimat“ gleichzusetzen und zu mahnen, Philosophie laufe Gefahr, „zu verschwinden und sich aufzulösen, wenn sie diese ureigenste Aufgabe nicht erkennt und annimmt“. ${ }^{109}$ Raum, Zeit und Mitmensch sind die Parameter, an denen sich der Heimat suchende Mensch orientiert. Geborgenheit, Ruhe und Vertrauen sind die Phänomene, die sich mit Heimat verbinden. ${ }^{110}$

103 So ein Teil eines Aufsatztitels von Klaus Weigelt, vgl. Weigelt 1984.

104 Waldenfels 1984, S. 194.

105 Waldenfels 1984, S. 206.

106 Waldenfels 1984, S. 203.

107 Alle Zitate Joisten 2004, S. 24.

108 Joisten 2004, S. 25.

109 Joisten 2004, S. 208.

110 „Der Mensch als Heim-weg ist durch ein Binden und Richten zu kennzeichnen. Das Binden meint einerseits ein Zurückgebundensein an eine ursprüngliche Heimat, die auf den Ort des Ursprungs verweist. Dieses Zurückgebundensein spricht sich andererseits im Sich-Binden des Menschen im konkreten Leben aus, das in allen Strukturelementen (Raum, Zeit und Mitmensch) 
Diesen Ansatz entwickelt Joisten zunächst in einem systematischen Teil, danach in der Auseinandersetzung mit Augustinus, Albert Camus und Vilém Flusser. Da auch in dieser Auseinandersetzung dezidiert keinem historischen, sondern einem systematischen Interesse gefolgt wird, können drei überhistorisch verstandene Modelle gebildet werden: erstens das von Augustinus repräsentierte Verständnis von Heimat als „Urphänomen“. Diese „Urheimat“ ziele auf das „Sein“ des Menschen und auf das religiöse Apriori der Heim-Kehr zu Gott. ${ }^{111}$ Zweitens die „Sehn-Suche des Menschen“, in welcher „der Mensch das Menschliche in sich oder außerhalb seiner sucht“, nicht mehr bei Gott. Für diese Suchbewegung stehe Camus. ${ }^{112}$ Drittens Heimat verwerfende Philosophien des „transhumane[n] Posteriori“ $^{\text {“113 }}$ wie die Medienphilosophie Flussers, die Joisten als ungeeignet und sogar teils als unsinnig ansieht. ${ }^{114}$

Auch wenn es Joisten um systematische Fragen geht, schränken historische Nachlässigkeiten die begriffliche Präzision ein. So wird Augustinus als zentraler Heimat-Philosoph in Anspruch genommen - „Das Denken von Heimat ist für Augustinus gleichbedeutend mit dem, was er unter echter Philosophie versteht“115 -, aber an keiner Stelle reflektiert, warum so unterschiedliche von Augustinus verwendete Vokabeln wie ,habitatio', ,patria', ,domus‘ oder ,terra' ohne Umschweife für eine Philosophie von Heimat in Anspruch genommen werden können. Dasselbe Bild bietet der Umgang mit den Texten von Camus: Einerseits wird die Wortwahl von Camus zum Argument, ${ }^{116}$ andererseits wird ohne Verweis auf das Übersetzungsproblem auf eine deutschsprachige Übersetzung zurückgegriffen und nicht einmal erwähnt, welche französischen Worte im Original stehen. Es zeigt sich damit in der konkreten Durchführung, wie ein phänomenologisch argumentierender Ansatz wie der Joistens Gefahr laufen muss, Setzungen vorzunehmen, die historisch möglicherweise gar nicht gedeckt oder zumindest erklärungsbedürftig sind.

Ansätze, die das ,Heimatgefühl‘ oder aber auch das Gefühl der Heimatlosigkeit als eine menschliche Grundkonstante verstehen und Heimat insofern natu-

sichtbar gemacht werden kann und besonders deutlich in den Phänomenen Geborgenheit, Ruhe und Vertrauen hervortritt.“ Joisten 2004, S. 52.

111 Joisten 2004, S. 202.

112 Joisten 2004, S. 205.

113 Joisten 2004, S. 207.

114 „Ich gehe so weit zu behaupten: Flusser versteht selbst nicht, was er sagt.“ Joisten 2004, S. 281.

115 Joisten 2004, S. 210.

116 Joisten 2004, S. 245. „Hier verwendet Camus an vier verschiedenen Stellen das Wort ,Heimat““. 
ralisieren, oder wie bei Christoph Türcke durch den Bezug auf den Mutterleib sogar biologisieren, werden bis heute verfolgt. ${ }^{117}$ Soziologische und sozialpsychologische Forschungen zum Thema Heimat weichen von solchen Ansätzen einerseits fundamental ab. Denn indem Heimat als sozial geformte Kategorie konzeptualisiert und als Resultat aktiver Gestaltung in einem Prozess der Beheimatung begriffen wird, Heimat also vor allem als Sozialbezug gedacht wird, erforschen solche Ansätze „Beheimatung statt Heimat“. ${ }^{118}$ Heimat wird als „subjektive Konstruktion“"119 verstanden, die eng mit Identitätsbildungsprozessen zusammenhängt.

Andererseits gibt es auch Schnittstellen. Denn ob als anthropologische, ontologische, phänomenologische Kategorie oder als Vergesellschaftungspraxis verstanden, ob als menschliche Grundkonstante naturalisiert oder als wandelbares sozio-kulturelles Konstrukt konzeptualisiert: Konsensuell ist, dass der Mensch eine wie auch immer geartete Heimat braucht. Um die wissenschaftliche Beschreibung, aber auch das offene Plädoyer für ein Beheimatetsein des Menschen geht es im Kern in allen Ansätzen.

Folglich ist ihnen auch gemeinsam, dass sie einen operationalisierbaren Begriff für dieses Anliegen brauchen. Entweder, indem sie ,Heimat' verwenden, oder, indem sie den Begriff durch andere Begriffe ersetzen: als Anthropologie des affektiven Raumbezugs, als Ontologie der ,Urheimat' oder als soziale Praxis der Beheimatung. Alle Ansätze wissen dabei um die historische und semantische Vielschichtigkeit des Begriffs, um seine Ideologisierungen und Funktionalisierungen und beziehen diese mehr oder weniger stark in ihre Überlegungen ein. Sie gehen aber davon aus, dass sich in den historischen oder semantischen Schichtungen ein analytisch verwendbarer Heimat- oder Beheimatungsbegriff verbirgt, der freigelegt werden kann.

117 Für philosophische Ansätze, die das Heimatgefühl zur menschlichen Grundkonstante erklären, vgl. Klose 2013. Für Ansätze, die von einer konstitutiven Heimatlosigkeit des Menschen ausgehen, vgl. Türcke 2006. Christoph Türckes Essay Heimat. Eine Rehabilitierung argumentiert, dass der Mensch, nachdem er seine ,erste Heimat - den Mutterleib - habe verlassen müssen, von einer Sehnsucht nach Beheimatung angetrieben ist, die konstitutiv unerfüllbar sei.

118 So ein Aufsatztitel von Beate Binder, vgl. Binder 2000. Vgl. auch Binder 2007, Binder 2008 und Seifert 2011/2012. Schon der Soziologe Wilhelm Brepohl verweist darauf, dass der Mensch Heimat ,in seinem Bewußtsein und durch sein Verhalten immer wieder von neuem auf[baut]“ und Heimat damit „ein Vorgang, ein Prozeß“" sei. Brepohl 1965, S. 54.

119 So der Teil eines Aufsatztitels von Beate Mitzscherlich, vgl. Mitzscherlich 2019. Vgl. auch Mitzscherlich 1997. Mitzscherlich geht es um die Erforschung von menschlichen Bedürfnissen, durch die Heimat individuell integriert wird, das Bedürfnis nach Kontrolle, Gemeinschaft und Stimmigkeit. 
Auch solche Forschungsarbeiten zu Heimat, die stärker als die bisher genannten an einer Historisierung und kulturgeschichtlichen Einordnung des Begriffs interessiert sind, verbindet, bei sonst ganz unterschiedlichen Herangehensweisen und Qualitäten, die teils explizite, teils implizite methodische Voraussetzung, Heimat als operationalisierbaren Begriff aufzufassen.

Michael Neumeyers geographischer Dissertation Heimat. Zu Geschichte und Begriff eines Phänomens von 1992 geht es einerseits um die Rekonstruktion historischer Begriffsverwendung, andererseits um die systematische Behandlung eines Phänomens. Die schmale Arbeit widmet ihren ersten Teil der geschichtlichen Entwicklung des Heimatbegriffs - wobei Neumeyer vornehmlich nicht an den Quellen arbeitet, sondern die Ergebnisse schon geleisteter Forschung referiert. Darauf aufbauend wird in einem zweiten Teil ein für die eigene Gegenwart tragfähiger Heimatbegriff entwickelt, der umweltbezogene und psychische Aspekte umfasst. Heimat ist für Neumeyer ,eine unmittelbare, alltäglich erfahrene und subjektive Lebenswelt, die durch längeres Einleben in ihre sozialen, kulturellen und natürlichen Bestandteile Vertrautheit und Sicherheit, emotionale Geborgenheit und befriedigende soziale Beziehungen bietet und - auch dadurch - insbesondere verschiedene (Grund-)Bedürfnisse befriedigt“. ${ }^{120}$

Auf Grundlage welcher Prämissen Neumeyer den Kern dessen, was für ihn Heimat ist, aus der historischen Entwicklung des ,Phänomens“ herausarbeiten konnte, wird nicht recht deutlich. Die Arbeit behauptet jedenfalls, man könne zum Phänomen vordringen, indem man sich seiner nur verstellenden historischen Äußerungsformen entledige. Mit der „Forderung nach Beseitigung allen überflüssigen zeitgebundenen und insbesondere ideologischen Ballastes“ glaubt Neumeyer, „zu einer konkreten Beschreibung des Heimatphänomens zu gelangen“. ${ }^{121}$ Die historische Begriffsgeschichte dient Neumeyer demnach dazu, „die zeitlichen und ideologischen Veränderungen“ zu erfassen, um „den Begriffs,Ballast" vom eigentlich Wesentlichen trennen $\mathrm{zu}$ können“. ${ }^{122}$ Insofern steht Neumeyers Arbeit, anders als der Titel vermuten lässt, nicht in der Forschungstradition der Begriffsgeschichte, sondern ist im Grunde eine Anti-Begriffsgeschichte, die an einen von seinen historischen Realisierungen unabhängigen Sinn glaubt und am Ideal einer endgültigen Terminologie festhält, ohne allerdings methodisch nachvollziehbar zu machen, wie dieser gewonnen wird.

Andrea Bastians linguistische Dissertation mit dem Titel Der Heimat-Begriff. Eine begriffsgeschichtliche Untersuchung in verschiedenen Funktionsbereichen der

120 Neumeyer 1992, S. 127.

121 Neumeyer 1992, S. 4.

122 Neumeyer 1992, S. 5. 
deutschen Sprache von 1995 spielt in einer anderen Liga. Die differenziert angelegte Arbeit geht weit über historische Wortforschung im engeren linguistischen Sinn hinaus und sieht Heimat zugleich als „Vielfalt ideengeschichtlicher, kultureller Erfahrungen“. ${ }^{123} \mathrm{Ihr}$ Ausgangsbefund ist die semantische Komplexität des Begriffs und ihr Anliegen ist es, dieser Komplexität in der Kombination aus linguistischer, kulturhistorischer und ideengeschichtlicher Begriffsgeschichte nachzugehen. Bastian denkt Kulturgeschichte vor allem in funktionalen Zusammenhängen, die sie in die Funktionsbereiche Alltag, Recht, Politik, Naturwissenschaft, Religion und Literatur gliedert. In diesen unterschiedlichen gesellschaftlichen Bereichen, das zeigt Bastian auf, weicht die Heimatsemantik teilweise stark voneinander ab. Es ist das Verdienst der Arbeit, diese semantische Varianz des Begriffs detailliert darzustellen.

Allerdings geht Bastian weniger von einer Überlagerung dieser verschiedenen Bedeutungen aus, wie das die hier vorliegende Studie tut, sondern eher von einem Nebeneinander verschiedener, voneinander unabhängiger Bedeutungen. Von ihrem eher statischen Verständnis gesellschaftlicher Funktionsbereiche, die kaum miteinander in Beziehung gesetzt werden, weicht Bastian nur in Bezug auf den Bereich ,Alltag“ ab. Sie kommt dabei zu dem Ergebnis, dass die Alltagsbedeutung allen anderen Semantiken historisch vorgängig gewesen sei und dass die Bedeutungen der einzelnen Funktionsbereiche teilweise wieder auf die Alltagsbedeutung zurückgewirkt hätten. In einer Begriffsgeschichte - und nichts anderes unternimmt Bastian - kann indes nur über Textzeugnisse geredet werden, aber gerade ältere Textzeugnisse sind in den seltensten Fällen Dokumente der Alltagssprache. Bastian kann ihre methodisch zentrale These daher kaum belegen. Sie geht vielmehr von der Vorannahme aus, Heimat habe sich immer schon durch ihren räumlichen, sozialen und emotionalen Bezug ausgezeichnet, wobei sie auf anthropologische Begründungen zurückgreift. ${ }^{124}$

Auch Bastian geht somit von einer im Alltagsverständnis vorgängigen „Idee von Heimat aus. Alle anderen Funktionsbereiche bilden gewissermaßen Abweichungen von dieser Idee aus, die auf diese selbst wieder Einfluss nehmen können. Wenn es allerdings doch wieder um eine nur vage definierte, nicht an Textzeugnissen feststellbare Idee geht, verliert Begriffsgeschichte an Kontur. Das zeigt sich auch im Detail, wenn Bastian in ihren Textbeispielen im „Funktionsbereich Literatur" solche Texte verwendet, in denen der Begriff Heimat zu einem guten Teil gar nicht explizit vorkommt. Laut Bastian „thematisieren“ diese Texte die „in-

123 Bastian 1995, S. 1.

124 Vgl. Bastian 1995, S. 24. 
haltliche[n] Aspekte des Heimat-Begriffs““, ${ }^{125}$ aber diese inhaltlichen Aspekte werden gar nicht systematisch entwickelt. Da Bastian beispielsweise die Ablehnung der Stadt in der Idyllendichtung des 18. Jahrhunderts als repräsentativ für Heimatvorstellungen ansieht, wird Salomon Geßner für einen Heimatbegriff herangezogen, der, bleibt man beim Begriff, bei ihm an keiner Stelle zu finden ist. Methodisch begründet kann die Quellenauswahl für einen begriffsgeschichtlichen Ansatz aber nur sein, wenn man beim Begriff bleibt; auch hier wird die bei Bastian im Alltagsverständnis angesiedelte Vorstellung einer ,Idee‘ von Heimat der Arbeit methodisch zum Verhängnis.

Das für ein breiteres Publikum geschriebene, aber wissenschaftlich ausgewiesene Buch der Literaturwissenschaftlerin Susanne Scharnowski Heimat. Zur Geschichte eines Missverständnisses (2019) verfolgt mit seiner historischen Rekonstruktion der Genese von unterschiedlichen Heimatentwürfen durch die letzten zwei Jahrhunderte konsequent ein Ziel: den Begriff von historischen Vorurteilen zu befreien und seine Gegenwartstauglichkeit zu prüfen. Scharnowski will gegen ein aus ihrer Perspektive fortwährendes Missverständnis von Heimat angehen, nach dem beispielsweise romantische Heimatentwürfe im Kurzschluss mit der Blut-und-Boden-Ideologie des Nationalsozialismus zusammengebracht würden und Heimat bis heute dem Verdacht des Reaktionären ausgesetzt sei. Unter der Prämisse eines dominanten Vorbehalts insbesondere intellektueller Kreise gegenüber Heimat - die meiner Meinung nach spätestens seit dem Beginn des 21. Jahrhunderts nicht mehr haltbar ist (vgl. III) - entwickelt sie dann historische Gegenargumente, die Heimat historisch rehabilitieren sollen.

Die Arbeit ist von der These geleitet, „dass es in der deutschen Geschichte nicht etwa ein Zuviel an Heimat gibt, sondern eher einen Mangel. Die stete Rede über Heimat wäre dann eher Symptom einer Leerstelle statt Ausdruck von Gewissheit. “126 Heimat sei auch historisch vor allem ein Konzept gewesen, das in Reaktion auf die negativen Folgen der Modernisierung entstanden sei. Die Heimatbewegung um 1900 sei beispielsweise nicht so reaktionär, wie ihr oft unterstellt werde, ${ }^{127}$ sie habe vor allem den Preis aufgezeigt, der für den materiellen

125 Bastian 1995, S. 174.

126 Scharnowski: Heimat, 2019, S. 16.

127 Scharnowski zufolge herrscht ein weitgehend unkritisches, fortschrittsverherrlichendes Moderne-Bild der Jahrhundertwende vor, innerhalb dessen die Heimatbewegung im rückwärtsgewandten, anti-modernistischen Licht erscheine (vgl. Scharnowski: Heimat, 2019, S. 64). So richtig der Hinweis ist, dass die Heimatbewegung vielmehr als Teil der Moderne zu betrachten ist, so wenig wird erwähnt, dass diese differenzierte Sicht auf die Zeit um 1900 Forschungskonsens ist, vgl. beispielsweise Kramer, und dass die starke These (oder auch nur der rhetorische Kniff), ein ,Missverständnis‘ aufklären zu müssen, dazu führt, die kritischen Seiten der Heimatbewegung 
Wohlstand einiger zu zahlen war: gravierende ökonomische und soziale Umwälzungen in allen gesellschaftlichen Bereichen, die Entfremdung, Umweltzerstörung und die Zerstörung sozialer und gesellschaftlicher Bindungen mit sich brachten. Die Funktion von Heimat sei es historisch gewesen, diesen Umwälzungen etwas entgegenzusetzen, und diese Funktion könne und solle Heimat auch in der unmittelbaren Gegenwart übernehmen. Heimat könne als dynamisches und zukunftsorientiertes Konzept verstanden werden, mithilfe dessen konkrete räumliche und soziale Gefüge nach menschlichen Bedürfnissen gestaltet werden können.

Bei aller Bereitschaft, auch die historischen Verwerfungen zu beschreiben, die bestimmte Funktionalisierungen von Heimat hervorgebracht haben, führt die Arbeit immer die Prämisse eines ideologiefreien (und zu verteidigenden) Kerns von Heimat mit. So gilt es für Scharnowski durchaus zu untersuchen, „welche Akteure mit welchen expliziten oder impliziten politischen oder ideologischen Absichten sich jeweils auf Heimat berufen“. Auf diese Weise lasse sich eher eingrenzen, ,in welchen Zusammenhängen von genuinen Heimatbedürfnissen oder Heimaterfahrungen ,von unten' auszugehen ist und wann eher von einer Heimatideologie ,von oben' gesprochen werden muss". ${ }^{128}$ Diese Trennung ist allerdings schwierig, zumal ja gerade die vorgebliche Heimatverbundenheit der einfachen Leute ,von unten' ein zentraler ideologischer Hebel im Nationaldiskurs war. So bleibt auch bei dieser Arbeit die Frage offen, in welchem Verhältnis das eingeklagte menschliche Heimatbedürfnis, die Geschichte von Heimat und Heimat als operationalisierbarer Begriff stehen.

Das Bedürfnis, sich eine Heimat $\mathrm{zu}$ geben, verfolgen auch andere Forschungsarbeiten der letzten Jahre. Selbst im Kontext jüdischer Studien, in denen der Begriff Heimat oft eher gemieden wurde, lässt sich dies beobachten. Die Herausgeber des Buches Spiritual Homelands. The Cultural Experience of Exile, Place and Displacement among Jews and Others (2019) interessieren sich im Kontext von (jüdischem) Exil und Diaspora beispielsweise nicht mehr primär für die Erfahrung der Heimatlosigkeit, sondern für das Finden von Heimat als kulturell produktiven und selbstermächtigenden Akt: „[T]he experience of remaking

um 1900 fast ganz auszublenden: So wird beispielsweise die Heimatkunde im Kontext der Modernekritik erwähnt, ihre sehr enge Verflechtung mit nationalistischen und völkischen Positionen aber nicht erwähnt; ebenso wird in der Darstellung des sogenannten Heimatschutzes verfahren (vgl. Scharnowski: Heimat, 2019, S. 66-67). Gerade die Ambivalenzen des Heimatdiskurses um 1900 sind aber interessant.

128 Scharnowski: Heimat, 2019, S. 13. 
a home in a chosen homeland could be socially and culturally productive acts“. ${ }^{129}$ Heimat wird ab den 2000er Jahren immer wieder auch als dynamisches, räumliche Begrenzung transzendierendes Konzept interpretiert, an das man positiv anschließen will: „In such thinking Heimat ceases to be conceived either as the place of origin or a utopian place of arrival, becoming instead a frame of mind: the commitment of citizens to the process of making a liveable social space. Man may be territorial, but the territory keeps changing. “130 Heimat soll demnach nicht mehr rein begrenzter und ausschließender Ort sein, sie kann in dieser Perspektive beispielsweise auch für eine inklusive soziale Praxis stehen. Insbesondere mithilfe des methodischen Settings des ,spatial' oder ,topographical turn' und von Hybriditätstheorien der Cultural Studies versuchen verschiedene Ansätze, Heimat als neutralen, methodisch brauchbaren Begriff $\mathrm{zu}$ behandeln und ihn von Vorstellungen der Begrenzung, Ausgrenzung oder des Nationalismus zu befreien. ${ }^{131}$

So unterschiedlich alle bisher vorgestellten Ansätze sind, sie stehen in Beziehung zueinander, insofern sie trotz der immer wieder hervorgehobenen Unschärfe des Begriffs an einem bestimmbaren Kern bzw. einer definierbaren Idee von Heimat festhalten. Die Frage, ob dieser Kern dann vom historischen ,Ballast“ befreit und damit gewissermaßen freigelegt werden soll oder sich gerade andersherum durch die Rekonstruktion seiner historischen Bedeutung ergibt, wird dabei unterschiedlich beantwortet. Teilweise wird Heimat mit anthropologischen oder phänomenologischen Argumenten naturalisiert, teilweise mit sozialpsychologischen oder raumtheoretischen Ansätzen als dynamisches Konzept begriffen, immer aber wird an Heimat - oder an Ersatzbegriffen wie dem der affektiven Territorialität oder dem der Beheimatung - auch im Sinne eines operationalisierbaren Begriffs festgehalten.

Die Einsicht in die starke Anfälligkeit des Begriffs für Ideologisierungen und in die Schwierigkeit, ihn zu definieren und $\mathrm{zu}$ theoretisieren, kann auch zu gegenteiligen methodischen Entscheidungen hinsichtlich des Umgangs mit ihm

129 Biemann/Cohen/Wobick-Segev 2019, S. 5. Das Sich-Heimat-Geben wird, wenn auch nur als imaginärer Akt, zur Selbstermächtigung: ,the creative imagination of an expanded self beyond the facts of natural kinship and given place. Spiritual homelands, however naïve and imaginary they may be, are works of self-formation and ,self-othering that question existing geographies and cultural-political orders. They are paces of elective affinity and imagined familiarity. But this does not render them less real, or ,authentic“. "Biemann/Cohen/Wobick-Segev 2019, S. 2. Diese positive Deutung von Heimatentwürfen wird auch hier anthropologisch begründet: „The emotional need for a home (and a homeland) is linked directly to a sense of belonging, which is in turn created through our affective attachments.“ Biemann/Cohen/Wobick-Segev 2019, S. 6.

130 Boa/Palfreyman 2000, S. 195.

131 Vgl. Eigler 2012; Eichmanns 2013; Eigler 2014; Bland/Smale/Weiss-Sussex 2019. 
führen. Gerade ideologiekritische Ansätze ziehen es vor, Heimat nicht inhaltlich zu bestimmen, sondern sie über ihre Funktionalisierungen $\mathrm{zu}$ beschreiben.

Andreas Schumanns Habilitationsschrift Heimat denken. Regionales Bewußtsein in der deutschsprachigen Literatur zwischen 1815 und 1914 von 2002 geht diesen Weg. Die Studie untersucht aus literaturwissenschaftlicher Perspektive den wechselseitigen Einfluss von nationalem und regionalem Denken im 19. Jahrhundert, der seit 1990 im Fokus der historischen Forschung steht. ${ }^{132}$ Schumann befragt literarische Heimatdarstellungen in unterschiedlichen Medien (Anthologien, Almanachen und Jahrbüchern literarischer Vereine) und Gattungen (Gedichten, Sagen, Volksliedern, Landschafts- und Sittenbildern, literarisch-historiographischen Mischformen, Mundartdichtung). Anhand einer breiten Materialbasis kann Schumann belegen, dass sich die vorgebliche Besonderheit der in den literarischen Texten beschriebenen Regionen als fast austauschbares Muster erweist, in das wahlweise die Alpen oder die Nordsee, die Lüneburger Heide oder der Thüringer Wald eingetragen werden können. Gerade die Gleichförmigkeit des jeweils nur variierten literarischen Musters verweist auf die Zusammengehörigkeit der Teile, und so sind die literarischen Heimatdarstellungen nur als kaum abweichende Ausformungen des Ganzen lesbar, auf das sie verweisen: die Nation. ${ }^{133}$

Schumann nimmt damit einen zentralen sozial- und ideologiehistorischen Aspekt von Heimat in den Blick. Heimat wird nicht als Gegenstand aufgefasst, der von der Literatur beschrieben wird, sondern als Konstrukt, das von der Literatur überhaupt erst erschaffen wird, und zwar zu bestimmten Zwecken: Heimat sei ein „literarisches Konstruktionsprinzip für gemeinschaftsstiftende affektive Einstellungen“. ${ }^{134}$ Mit seiner rein konstruktivistischen Auffassung von Heimat befreit sich Schumann von essentialistischen Vorannahmen, setzt aber seinerseits andere stark begrenzende methodische Prämissen. Denn er stellt von vornherein fest, zu welchem Zweck Heimat literarisch konstruiert wird: Heimat stifte ideolo-

132 Celia Applegates historische Studie A Nation of Provincials. The German Idea of Heimat deutet die Idee der Heimat als Mediatorin zwischen regionaler Zugehörigkeit und abstrakter Nationalidee, vgl. Applegate 1990 (in deutscher Übersetzung Applegate 2007). Auch der Historiker Alon Confino kommt in seiner Studie The Nation as a Local Metaphor zum Zeitraum 1871-1918 zu dem Ergebnis, dass Heimat eine zentrale Funktion für den nationalstaatsbildenden Prozess übernommen habe. Dabei vermittelte sie einerseits lokales Leben und abstrakte Nation, repräsentierte ab 1871 aber auch zunehmend die Nation. Deutschland wurde eine „Nation of Heimats“. Confino 1997, S. 95. Confino versteht Heimat als Teil des Moderne-Projekts, in dem lokale und nationale Identität miteinander versöhnt werden sollten.

133 Differenzen beobachtet Schumann eher zwischen Peripherie und Zentrum: Je stärker die Randlage, umso mehr werde das Allgemeine betont, je stärker die Kernlage, umso mehr das Partikulare, vgl. Schumann 2002, S. 65.

134 Schumann 2002, S. 79. 
gisch motiviert Gemeinschaft, und zwar über die affektive Besetzung des Raums. Gerade Literatur biete sich für diese ideologische Indienstnahme an, und insbesondere die im 19. Jahrhundert weit verbreiteten literarischen Anthologien eigneten sich in ihren Gattungsmerkmalen dafür, denn sie bieten „häufig deutliche Lese- und Gebrauchsanweisungen durch die in den Motti, Vorworten oder Widmungen präsentierte Einbettung in bestimmte situative Kontexte““. ${ }^{135}$ Ideologiekritik heißt bei Schumann auch, dass bestimmte Trägerschichten, Akteure und Profiteure der durch , heimatliche Literatur` verbreiteten Heimatideologie benannt werden können. ${ }^{136}$ Unter ,heimatlicher Literatur' versteht Schumann solche Texte, die die Darstellung ländlicher Regionen unter das Label ,Heimat‘ stellen und affektiv besetzen. Mit dieser Engführung der Heimatfrage auf Regionalliteratur schließt Schumann, teilweise kritisch, an die wichtigen Forschungen Norbert Mecklenburgs zu Regionalismus und Moderne in der Literatur an. ${ }^{137}$

So zwingend Schumanns Beobachtung ist, dass es gerade im 19. Jahrhundert einen ausgeprägten literarischen Regionalismus gegeben hat und dass dieser ausgesprochen viele Schnittstellen zu verschiedenen Heimat- und Nationaldiskursen aufweist, so offensichtlich ist, dass sich literarische Heimatentwürfe nicht im Regionalismus erschöpfen. Das Funktionsverhältnis, innerhalb dessen Heimat für die Zwecke der Nationalstaatsidee instrumentalisiert wurde, kann Schumann bezogen auf seine Quellen plausibel beschreiben, aber eine umfassende Aufklärung des Verhältnisses von Heimat und Literatur ist damit noch nicht gegeben. Die Klarheit der Argumentation besticht gerade im Vergleich $\mathrm{zu}$ anderen literaturwissenschaftlichen Arbeiten, die an der semantischen Vieldeutigkeit des Be-

135 Schumann 2002, S. 23. Im Kapitel zu ,Anlässen heimatlicher Dichtung“ führt Schumann aus, dass insbesondere Herrscherjubiläen, Stadtgründungsfeste und ähnliche Feierlichkeiten die Veröffentlichungsdichte ,heimatlicher Literatur' beförderten.

136 Die „Trägerschicht des heimatlichen Regionaldiskurses“ ist nach Schumann „strukturell identisch mit der den Nationalismus befördernden Gebildeten. Daraus ist zu vermuten, daß auch die Mittel der Distribution und die entsprechenden Institutionen wie die verwendeten Medien ebenfalls in Analogie zu denen einer national-patriotischen Kultur in Erscheinung treten.“ Schumann 2002, S. 22.

137 Norbert Mecklenburgs Studie über Erzählte Provinz. Regionalismus und Moderne im Roman arbeitet aus guten Gründen explizit nicht mit dem Heimatbegriff, weil er für die Darstellung der Region im Roman zwar Schnittstellen biete, aber keinesfalls Deckungsgleichheit und zudem weniger objektivierbar sei. In seinem Vorwort setzt sich Mecklenburg mit der mangelnden Belastbarkeit des Heimatbegriffs für seine Studie auseinander: „,Heimat‘, als Wort und Begriff in spezifisch deutschen Traditionen verankert, ist weit mehr noch als ,Provinz ein ideologisches Polysem. Während sich im Provinzbegriff geschichtlich-geographische Objektivität und subjektives, kulturell vorgeformtes Deutungsmuster verflechten, stellt ,Heimat‘ einen Relationsbegriff dar, eine gedankliche Leerform, die desto mehr emotionale Konnotationen an sich zieht, je geringer ihr objektiver Sachgehalt ist.“ Mecklenburg 1982, S. 17. 
griffs und den damit verbundenen methodischen Problemen einerseits, an der Materialfülle andererseits scheitern, ${ }^{138}$ aber sie ist damit erkauft, über vieles, das offensichtlich zum Thema gehört, nichts sagen zu können.

Auch Peter Blickles im selben Jahr wie Schumanns Studie erschienenes Buch Heimat. A Critical Theory of the German Idea of Homeland verfolgt einen ideologiekritischen Ansatz. Anders als Schumann beschränkt er sich aber nicht auf ein bestimmtes Textkorpus oder eine bestimmte Form der Funktionalisierung von Heimat, sondern hat den Anspruch, die deutsche ,Ideengeschichte، von Heimat insgesamt einer Untersuchung im Geist der Kritischen Theorie zu unterziehen. ${ }^{139}$ Zunächst stellt Blickle fest, dass Heimat kein tragfähiger analytischer Begriff sein kann. Auch der jüngeren Forschung zum Thema wirft er vor, nicht kritisch-analytisch mit dem Begriff umzugehen. ${ }^{140}$ Dies hänge historisch mit einer langen Deutungsgeschichte von Heimat zusammen, die sich immer schon mit einem Vorreflexiven verband. Blickle versteht Heimat als kulturelles Konstrukt, das auf der Behauptung beruhe, natürlichen Ursprungs zu sein: „To accept the notion of Heimat for constitutions of one's identity is a willing submission to a cultural construct that is perceived as a natural state of being." ${ }^{141}$ Die angebliche Unschuld des Begriffs hinterfragt Blickle; Heimat schließe immer eine deutsche Sehnsucht nach einem Ort der Unschuld mit ein, ${ }^{142}$ tatsächlich gelange aber jede Aufarbeitung der Idee von Heimat notwendig zu den dunklen Seiten der deutschen Geschichte ${ }^{143}$ und damit auch zu verdrängter Schuld und unterdrückten Ängsten. ${ }^{144}$ Blickle sieht in Heimat vor allem ein ausgrenzendes und unterdrückendes Konzept deutscher Ideengeschichte. ${ }^{145}$

138 Das eindrücklichste Beispiel in dieser Hinsicht ist Schwarz 2007. Positiv hervorzuheben ist bei Schwarz allerdings, dass hier einmal die Virulenz des Heimatdiskurses um 1800 nicht auf den romantischen Diskurs verengt wird, sondern neben Hölderlin, Eichendorff und Heine auch bei Goethe und Schiller untersucht wird.

$139 \mathrm{Zu}$ den Bezügen zur Frankfurter Schule (Adorno, Horkheimer, Habermas) vgl. u.a. Blickle 2002, S. ix, S. 33-40, S. 81-82.

140 Die Forschung unterliege der stillschweigenden Annahme, Heimat könne nur von innen heraus verstanden werden: „The tacit assumption is that Heimat can only be understood from within. Therefore, true understanding can come out of only a form of identification, not from a form of analysis." Blickle 2002, S. 12.

141 Blickle 2002, S. 6.

142 „My study inquires into the uncanny and persistent German longing for a space of innocence that Heimat always implies [...].“ Blickle 2002, S. ix.

143 Vgl. Blickle 2002, S. 13.

144 „Heimat buries areas of repressed anxiety.“ Blickle 2002, S. 14.

145 Erforscht werden die „mentally created boundaries und exclusions“, welche die ,Idee“ der Heimat speziell „in German language and thought“ bewirkt habe. Blickle 2002, S. xi. 
Viele Beobachtungen von Blickle sind richtig - strukturelle Ausgrenzung, patriarchale Muster und verdrängte Ängste wird auch die hier vorliegende Studie an bestimmten Heimatentwürfen des 19. Jahrhunderts herausarbeiten -, sind bei ihm aber nicht Teil eines an den Gegenständen entwickelten Bildes, sondern bleiben zu oft Setzung. Während Schumanns Ideologiekritik sich auf ein konkretes Korpus und eine bestimmte Funktionalisierung von Heimat fokussiert und deshalb zu stichhaltigen und klaren - wenn auch in ihrer Reichweite begrenzten Ergebnissen kommt, gießt Blickle seine Ideologiekritik über sämtliche Erscheinungen von Heimat aus und verdeckt damit mindestens genauso viel, wie er sichtbar macht. Sein Buch von 2004 ist das letzte Beispiel für eine kategorische Ablehnung des Begriffs und Konzepts, oder wie er sagt, der ,Idee“ Heimat in der Wissenschaft, wie sie sonst eher noch in den 1990er Jahren $\mathrm{zu}$ finden war. ${ }^{146}$ Die Versuche, Heimat als wissenschaftsfähigen Begriff zu (re-)etablieren, dominieren insgesamt und nach Blickle dann fast gänzlich das Feld der Auseinandersetzung mit Heimat, wie gezeigt. ${ }^{147}$

Einen eigenen Weg geht Jens Korfkamp in seiner politikwissenschaftlichen Studie Die Erfindung der Heimat. Zu Geschichte, Gegenwart und politischen Implikationen einer gesellschaftlichen Konstruktion von 2006. Die in der Forschung unverständlicherweise kaum beachtete Studie zeigt, „daß ,Heimat“ eine zentrale gesellschaftliche Kategorie ist, die abgelöst vom Zusammenhang der subjektiv erlebten Lebenswelt zum identitätsstiftenden Grundstein eines Kollektivs werden kann“, und beschreibt, „warum „Heimat“ in einer solchen sozialen Konstruktion so erfolgreich war und ist““. ${ }^{148}$ Für Korfkamp ist die Bedeutung von Heimat Ergebnis von gesellschaftlichen Aushandlungsprozessen, die sich historisch sehr verschieden darstellen. Insofern Heimat Korfkamp als politische Kategorie gilt, werden naturalisierende Heimatauffassungen genauso wie Auffassungen, die Heimat über ihren subjektiven Charakter bestimmen, von vornherein ausgeschlossen. Die kritische Revision, der er die verschiedenen Funktionalisierungen von Heimat durch das 19. und 20. Jahrhundert hindurch unterzieht, dient ihm deswegen auch nicht dazu, die punktuelle historische Ideologisierung einer anthropologischen Grundgegebenheit bzw. eines allgemeingültig zu bestimmenden

146 Vgl. exemplarisch Gisela Eckers kritische Auseinandersetzung mit einem Aufsatz zu Heimat von Walter Jens: „Es ist sicherlich wichtig, zu analysieren und zu verstehen, was ,Heimat‘ bei Hölderlin und bei Fontane bedeutet, doch gegen Jens' Rehabilitierungsversuche muß man einwenden, daß die Poesie und der Glanz, den er im Gebrauch des Wortes vor seinem Mißbrauch feststellt, unrettbar verloren sind oder, genauer gesagt, verloren sein sollten.“ Ecker 1997, S. $24-25$.

147 Vgl. exemplarisch den Essay Heimat. Eine Rehabilitierung, Türcke 2006.

148 Korfkamp 2006, S. 17. 
Konzepts zu beschreiben, wie das eine große Zahl der vorliegenden Arbeiten zu Heimat unternimmt, sondern sie dient ihm dazu, die konstitutive „Abhängigkeit des Heimatbegriffs von sozialen und politischen Rahmenbedingungen und Konflikten zu verdeutlichen“ ${ }^{149}$ Es geht somit um den Nachweis der politischen Wirksamkeit von Heimatkonzeptionen. Eine wichtige Funktion, die sich mit diesem Ansatz verbindet, ist die Kritik an einem wissenschaftlichen Argumentationsmuster, das Identität und Gemeinschaft „durch die menschliche Bindung an ein bestimmtes Territorium [...] begründet und so naturalisiert“"150 und den ,homo socialis` auf problematische Weise zum territorialen Menschen umdefiniert.

Insgesamt versucht die Arbeit erstens, im historischen Durchgang solche und andere Heimatkonstruktionen zu rekonstruieren; sie versucht zweitens, diese Konstruktionen zu systematisieren, indem sie zwischen einem ,personal-subjektivistischen Heimatbegriff' und einem ,gesellschaftlich-objektivistischen Heimatbegriff' unterscheidet - und sie unternimmt es drittens auf der Grundlage von Jürgen Habermas' Theorie des kommunikativen Handelns, die zukünftige Ausbildung eines „gesellschaftsadäquaten“ Begriffs von Heimat zu fordern, „der sich an der Freiheit und Vernunft der Individuen orientiert“". ${ }^{151}$ Gewissermaßen gegen alle historischen Ausprägungen, auch die der eigenen Gegenwart, entwickelt Korfkamp aus der Idee heraus, dass Heimat immer schon Resultat gesellschaftlicher Aushandlungsprozesse war, den Anspruch, diesen Aushandlungsprozess unter den neuen Rahmenbedingungen einer „offenen Gesellschaft" ${ }^{\text {“152 }}$ auch zu neuen Ergebnissen zu führen. Korfkamp steht mit diesem Ansatz insofern solitär, als er auf eine wie auch immer geartete allgemeingültige Definition von Heimat verzichtet, ohne sich aber in reiner Ideologiekritik zu erschöpfen. Heimat soll als soziale Konstruktion historisch aufgedeckt werden, nicht um sie als solche zu entlarven, sondern um sie auf ihre Verwertbarkeit für den gegenwärtigen gesellschaftlichen Diskurs (im Verständnis Habermas') zu prüfen.

Was ergibt sich nun aus diesem Forschungsüberblick für eine neue, für noch eine weitere Studie zum Thema Heimat? Als folgenreiche Grundsatzentscheidung hat sich die Frage erwiesen, ob zu einer Definition von Heimat vorgedrungen und Heimat damit als methodisch belastbarer Begriff aufgefasst werden soll oder nicht. Die Studie wählt die zweite Möglichkeit. Heimat ist aufgrund ihrer semantischen Vieldeutigkeit als methodisch-analytischer Begriff nicht tauglich und an allen ihren Operationalisierungen hängen entweder problematische normative Vorannahmen oder Erkenntnisinteressen, die nicht auf die geschichtliche Di-

149 Korfkamp 2006, S. 11.

150 Korfkamp 2006, S. 13.

151 Korfkamp 2006, S. 199.

152 Korfkamp 2006, S. 202. 
mension von Heimat zielen. Vielversprechender scheint es für das Vorhaben der historischen Rekonstruktionsarbeit, keine Vorannahmen darüber zu treffen, was Heimat ist. Nur ohne voreilige Heimatdefinitionen wird sichtbar, wie vieldeutig die Semantiken und die Funktionalisierungsmöglichkeiten von Heimat waren und sind. Um zu Aussagen darüber zu gelangen, was Heimat historisch jeweils bedeutete, bedarf es keiner heuristischen Heimatdefinition.

Tatsächlich eröffnen sich mit dieser methodischen Vorentscheidung auch neue Sichtweisen. So wurde die religiöse Dimension der Heimatsemantik bisher vernachlässigt. Zwar wird die religiöse Bedeutung von Heimat meist erwähnt, aber kaum in der Weise auf die Begriffssemantik bezogen, dass deutlich würde, inwiefern ihre Virulenz über den eigentlich religiösen Bereich hinausreicht. Dies liegt möglicherweise auch daran, dass die inhaltlichen Vorannahmen - beispielsweise diejenige, Heimat als affektive Raumbezogenheit zu lesen - in der Regel quer zum religiösen Sinn stehen. Die Relevanz der religiösen Bedeutung von Heimat, die bis in die unmittelbare Gegenwart unbewusst weiterwirkt, ist eine der zentralen Erkenntnisse dieser Studie, die sich aus der ohne Heimatheuristik auskommenden Sichtung der Textzeugnisse ergeben hat. Das Gleiche gilt für die rechtliche Dimension der Heimatsemantik. Diese wird historisch stets vor dem Beginn des modernen Heimatverständnisses verortet, das dann als sentimentales charakterisiert wird. Dass aber tatsächlich das rechtliche Verständnis Teil der modernen Heimatsemantik bleibt, wurde bisher meist übersehen. In diesem Fall haben sich historische Vorannahmen als hinderlich dafür erwiesen, die Überlagerungen verschiedener Bedeutungen von Heimat wahrzunehmen.

$\mathrm{Zu}$ den verbreiteten Vorannahmen gehört, Heimat naturalistisch aufzufassen. Wenn dieser Weg hier nicht verfolgt wird, geht es nicht darum, die Bedürftigkeit des Menschen nach einem vertrauten Ort oder vertrauten sozialen Strukturen, nach transzendenter oder irdischer Geborgenheit in Frage zu stellen. Aber man muss fragen, was passiert, wenn solche Bedürfnisse oder gar anthropologischen Gegebenheiten mit dem Begriff Heimat bzw. als Heimatbezug gefasst werden. Wenn beispielsweise die menschliche Anlage zu Sesshaftigkeit und affektiver Ortsbezogenheit (die, wenn man von einer solchen ausgeht, durch eine Anlage zum Wandern, zur Bewegung und zur Veränderung ergänzt werden muss) nicht als solche untersucht wird, sondern als Heimatbezug, dann wird sie einerseits mit einem normativen Zusatz ausgestattet, andererseits in eine Unbestimmtheit gezogen, die offen für vieles, aber nicht für analytische Präzision ist.

Da der Begriff als systematische Kategorie unbrauchbar scheint, wird hier auch im engeren literaturwissenschaftlichen Zusammenhang nicht von ,Heimatdichtung“, ,Heimatliteratur‘ oder ,Heimatroman` gesprochen, Begriffen, die in der 
literaturwissenschaftlichen Forschung üblich sind; ${ }^{153}$ selbst die Epochenzuschreibung ,Heimatkunst‘ zerfällt bei näherem Hinsehen (vgl. II.3.3). ${ }^{154}$ Der Notwendigkeit literaturwissenschaftlicher Kategorisierungen lässt sich besser nachkommen, wenn explizit wird, was beispielsweise mit ,Heimatdichtung' jeweils gemeint ist: etwa die Gattung des Bauernromans oder der Dorfgeschichte, Mundartdichtung oder Regionalliteratur. ${ }^{155}$

Historisch war Heimat Konzept, Programm, Idee oder auch Teil sozialer Praktiken. Dies alles wird in dieser Studie historisch rekonstruiert: Mit Heimat werden Vorstellungen von Regionalität oder Territorialität, Identität, Abstammung oder Tradition konzeptualisiert. Heimat ist in der Heimatschutzbewegung oder der Heimatkunst Programm. Heimat ist Idee innerhalb einiger idealistischer subjekt- und geschichtsphilosophischer Entwürfe. Heimat hat teil an sozialen Praktiken, etwa dem sogenannten Schubwesen, mit dem Arme teils gegen ihren Willen in ihre ,Heimat‘ abgeschoben wurden. Ob Konzept, Programm, Idee oder soziale Praktik: Heimat kann in Teilen als solche beschrieben werden, aber erschöpft sich nicht darin - etwa, wenn Heimat zur Metapher wird. Heimat kann

153 In Peter Mettenleiters Studie zur ,Heimatdichtung ' kann man beobachten, wie diese von ihm selbst als „sehr unbefriedigend“ (Mettenleiter 1974, S. 8) bewertete Rubrizierung unter den Händen des Autors zerfällt. Denn die angestrebte Typologie der Heimatdichtung fußt am Ende nur auf einem (von der Studie selbst als solitär bewerteten) Autor, Jeremias Gotthelf, dessen positiv bewertete ,Heimatdichtung im weiteren literaturgeschichtlichen Verlauf über Berthold Auerbach bis Ludwig Ganghofer einer anwachsenden Korrumpierung ausgesetzt sei, so dass Mettenleiters literaturgeschichtlicher Abriss zur Diagnose einer „Destruktion der Heimatdichtung“ (so der Titel der Studie) gelangt, die den Anspruch der Typologie einer Gattung, die offensichtlich über einen einzelnen Autor hinaus gar nicht positiv bestimmbar ist, selbst untergräbt. 154 Karlheinz Rossbachers einschlägige Studie Heimatkunstbewegung und Heimatroman. Zu einer Literatursoziologie der Jahrhundertwende (1975) umgeht das Problem Mettenleiters, da er die Kategorie ,Heimatroman“ von Anfang an historisch eng mit der Heimatkunstbewegung um 1900 verknüpft. Rossbacher arbeitet Ähnlichkeiten der dargestellten Sozialmodelle, Handlungsstrukturen, Figurenzeichnungen und Erzähltechniken in ausgewählten Romanen zwischen 1887 und 1910 heraus, die er in Verbindung mit zeitgenössischen Programmatiken der Heimatkunst setzt. Wenn überhaupt, dann kann nur in diesem engen Verständnis die Kategorie ,Heimatroman sinnvoll verwendet werden. Wie schwierig es aber ist, Programm und Literatur in einen kohärenten Zusammenhang zu stellen, zeigt sich in der konkreten Konfrontation des Programmatikers Adolf Bartels mit der Autorin Clara Viebig, wie das letzte Kapitel der vorliegenden Studie zeigt (vgl. II.3.3). Auch Rossbacher arbeitet mit Viebigs Weiberdorf, ihm entgeht aber aufgrund seines Ansatzes das zur Heimatkunstprogrammatik geradezu quer stehende Potential des Textes.

155 Und will der Literaturwissenschaftler oder die Literaturwissenschaftlerin an der Decouvrierung von ideologisch korrumpierter Literatur arbeiten, sollte mit dem Begriff Heimatdichtung nicht implizit die Verbindung zum Trivialen unterstellt werden, denn selbst bei der Lektüre von Wilhelmine von Hillerns Geier-Wally könnten die Vorurteile über vermeintlich triviale Heimatliteratur enttäuscht werden. Vgl. Scharnowski: Geier-Wally, 2019. 
auch die unterschiedlichsten Funktionen erfüllen: politische und soziale Funktionen der Identitätsstiftung, moralische und ideologische der Wertevermittlung, religiöse des Transzendenzglaubens. Heimat kann die Funktion einer Kompensation übernehmen. ${ }^{156}$ Manchmal ist sie aber auch Teil eines ästhetischen Spiels, das gar keiner Funktionalisierung unterliegen will. Die Beschreibung dieser unterschiedlichsten Formen und Funktionen von Heimat gelingt am ehesten, wenn „Heimat' nicht als Objekt, sondern als wandelbare und opalisierende Rede beschrieben wird, die sich zu einem auch historisch stets in Bewegung bleibenden Diskurs formt.

Es liegt also nahe, die Rede von ,Heimat‘ als Diskurs im Sinne Foucaults zu begreifen. Das ginge mit einer Antwort auf die Frage einher, wie sich unzählige Aussagen innerhalb ganz unterschiedlicher thematischer und institutioneller Zusammenhänge miteinander verknüpfen lassen, denn die Verwendung des Wortes Heimat ist interdisziplinär und zieht sich durch alle gesellschaftlichen Bereiche. Foucault macht das Problem an seinem Forschungszusammenhang des Wahnsinns fest:

[Die] Gesamtheit der Aussagen [über den Wahnsinn] ist weit davon entfernt, sich auf ein einziges Objekt zu beziehen, das ein für allemal gebildet ist, und es unbeschränkt als ihren Horizont unerschöpflicher Idealität zu bewahren; das Objekt, das von den medizinischen Aussagen des 17. oder 18. Jahrhunderts als ihr Korrelat gesetzt worden ist, ist nicht identisch mit dem Objekt, das sich durch die juristischen Urteilssprüche und die polizeilichen Maßnahmen hindurch abzeichnet; [...]. Es sind nicht dieselben Krankheiten, um die es sich dort oder hier handelt; es sind nicht dieselben Irren, um die es geht. ${ }^{157}$

Die Rede über den Wahnsinn kann nicht als eine „gültige Einheit für die Konstituierung einer Gesamtheit von Aussagen“ aufgefasst werden, da sie völlig Disparates umfasst. Foucault will nicht Objekte bilden, die immer wieder zerfallen würden, sondern das „Spiel der Regeln“158 und die „Verteilungsgesetze“159 formulieren, welche den Diskurs formen. Nicht Begriffe und Themen, sondern die „Verstreuungen selbst zu beschreiben“160 ist sein Anliegen.

Dieses Anliegen, das freilich wieder neue Ordnungsbildungen hervorbringen muss, um zu Aussagen vorzudringen, kann bezogen auf Heimat heißen, dass zunächst ganz konkret zu ermitteln ist, was Heimat im jeweiligen Kontext be-

156 Den kompensativen Charakter von Heimat arbeitete maßgeblich Hermann Bausinger heraus, zuerst in Volkskultur und technische Welt von 1961. Vgl. Bausinger 1961, S. 87.

157 Foucault 1997, S. 49-50.

158 Beide Zitate Foucault 1997, S. 50.

159 Foucault 1997, S. 51.

160 Foucault 1997, S. 57. 
deutet, dass sich aus diesen Rekonstruktionen dann Gruppen von Bedeutungen ergeben, die sich im Lauf der Geschichte verändern und teils quer durch wissenschaftliche Disziplinen und gesellschaftliche Felder verlaufen. Die Aufgabe ist, mit möglichst wenig Vorannahmen ein Bild der unterschiedlichen semantischen Konstellationen von Heimat zu rekonstruieren und nach den Bedingungen zu fragen, wie und warum sich die Rede von Heimat jeweils unterscheidet und verändert. Diese Aussagen über Heimat formen sich $\mathrm{zu}$ einem historisch in Bewegung befindlichen Diskurs, der auch im historischen Querschnitt ausgesprochen diverse Verständnisse von Heimat enthält.

Anders als bei Foucault wird das Diskursverständnis der hier vorliegenden Arbeit über den Begriff zusammengehalten. Denn das Anliegen, ,Verstreuungen selbst zu beschreiben', kann ohne einen festen Anker selbst zu Verstreuung führen. Meine methodische Vorentscheidung ist daher, in der Quellenauswahl streng bei den Texten zu bleiben, die den Begriff der Heimat verwenden. Heimat, so meine Vorgabe, ist alles das - und nur das -, was historisch so genannt wurde. Die unterschiedlichen Reden von dem, was explizit Heimat hieß, bilden dann den Heimatdiskurs. Dieser Ansatz bietet den größtmöglichen Verzicht auf Vorannahmen und kann an die Forschungen zur historischen Semantik anschließen, wie sie sich im Lexikon Geschichtliche Grundbegriffe von Otto Brunner, Werner Conze und Reinhart Koselleck manifestiert und insbesondere durch die Arbeiten Kosellecks methodisch reflektiert und praktisch angewandt wurde. Die von ihm identifizierten Grundbegriffe dürfen „nicht auf überzeitliche Ideen oder Probleme festgelegt werden [...], auch wenn wiederkehrende Bedeutungsstreifen auftauchen können“. ${ }^{161}$ Der Begriff enthält nach Koselleck „verschiedene Zeitschichten, und deren Bedeutungen haben verschiedene Dauer“. ${ }^{162}$ Nicht die Geschichte individueller Gebräuche eines Wortes kann geschrieben werden, aber die den Begriffen „innewohnende komplexe temporale Struktur“ ermöglicht es, „die Geschichte dieser temporalen Schichten von Bedeutungen“163 zu schreiben.

Bezogen auf Heimat schlagen diesen Weg auch Gunther Gebhard, Oliver Geissler und Steffen Schröter vor, sie wollen mit ihrer historischen Begriffsarbeit

die Deutungstraditionen als solche ernst nehmen und dann jene Rahmenbedingungen erfragen, innerhalb derer diese Traditionen aufkamen, fortgeschrieben wurden oder es $\mathrm{zu}$ Brüchen, Transformationen, Aufmerksamkeitsverschiebungen und Neuakzentuierungen gekommen ist. So kann die Frage danach erörtert werden, was zu bestimmten Zeiten Heimat war bzw. was als Heimat vorgestellt wurde. ,Heimat‘ würde mithin als eine historische und

161 Koselleck 2006, S. 100.

162 Koselleck 2006, S. 91.

163 Koselleck 2006, S. 91. 
dementsprechend $z u$ historisierende Semantik begriffen, die ihre Plausibilität aus je spezifischen historischen Umständen gewinnt. ${ }^{164}$

Historische Begriffsarbeit bedeutet die Beachtung des Wortlauts. Nur wo ,Heimat ${ }^{\star}$ steht, geht es im engeren Sinn um Heimatsemantiken. Das heißt nicht, dass ihre Verwandtschaft mit anderen Begriffen für die Untersuchung keine Rolle spielt, im Gegenteil. Erstens gibt es ein semantisches Umfeld von Heimat, das einbezogen werden muss. Es umfasst Begriffe wie Vaterland und Vaterhaus, Zu-Hause-Sein und Daheim, Heim, Herd und das Heimelige; das Heimweh gehört ebenfalls dazu und gerade zu diesem Begriff, der sich in der Medizin, der Religion und der Literatur findet und dort seine eigene Geschichte hat, bedürfte es in seinen Bezügen zum Begriff der Heimat einer eigenen Studie. ${ }^{165}$ Immer wieder gibt es Texte, bei denen eine fast synonyme Verwendung der genannten Begriffe zu beobachten ist. ${ }^{166}$ Andere Texte zeigen eindrucksvoll, dass man keinesfalls von einer solchen Deckungsgleichheit ausgehen kann. Das semantische Umfeld von Heimat kann nicht mit Heimat gleichgesetzt, es muss in ein Verhältnis gesetzt werden. Und diese Verhältnisbestimmung ist ihrerseits eine ausgesprochen komplexe histori-

164 Gebhard/Geisler/Schröter 2007, S. 12. In ihrem Beitrag Heimatdenken: Konjunkturen und Konturen entwickeln die Autoren wichtige Überlegungen zu diesem Ansatz.

165 Zur interdisziplinären Begriffs- und Diskursgeschichte des Heimwehs vgl. vor allem die Grundlagenarbeit von Simon Bunke, vgl. Bunke 2009. Zahlreiche sprachhistorische Arbeiten zur Wortgeschichte von ,Heimweh` entstehen schon Anfang des 20. Jahrhunderts, vgl. exemplarisch Kluge 1902. Für medizinhistorische Forschung seit Beginn des 20. Jahrhunderts vgl. exemplarisch Jaspers 1909, Brunnert 1984, Roth 1993, Schmid-Cadalbert 1993. An den diskursgeschichtlichen Schnittstellen von Medizin- und Literaturgeschichte arbeiten schon vor Bunke etwa Starobinski 1963, Kittler 1986, Gröf 2000. Die breite angloamerikanische kulturwissenschaftliche Forschung zur Nostalgie verweist zwar in der Regel auf die medizinhistorische Vorgeschichte, interessiert sich aber weniger für die Schnittstellen, die sich dadurch mit der von ihr untersuchten Literatur ergeben, vgl. exemplarisch Boym 2001, Wagner 2005. Die genannte Forschung geht in der Regel nicht auf die Bezüge zwischen Heimweh- und Heimatsemantiken bzw. -diskursen ein. Unterbelichtet bleibt meist auch der wichtige Anteil religiöser Semantiken des Heimwehs für die Begriffsund Diskursbildung. Vgl. in dieser Studie auch I.2.3, II.1.1.2, II.1.2 und II.2.

166 Für die Begriffskette Heimat - Heimweh - zu Haus - heimischer Herd - Daheim vgl. Helene Krügers Gedicht Am eignen Herd: „Wohl lacht uns das Leben, die Welt ist so schön, / wir wirken und streben, wir kommen und geh'n; / doch tilgt keine Ferne, verlöscht keine Zeit / das Heimweh des Herzens nach ,Seßhaftigkeit‘. / Der Mensch braucht ein Plätzchen - und wär’s noch so klein -, / von dem er kann sagen: ,Sieh hier, das ist mein! / Hier leb' ich, hier lieb’ ich, hier ruhe ich aus, / hier ist meine Heimat - hier bin ich zu Haus! / O trauliche Stätte, o heimischer Herd, / wie bist du dem deutschen Gemüte so wert! / Des menschlichen Strebens uredelster Keim, / es liegt in dem einzigen Wörtlein: ,Daheim!““ Hawel 1930, S. 82. 
sche Arbeit, da die Beziehung der Begriffe ebenfalls einem Wandel unterliegt (vgl. I.2).

Die Grenzen herkömmlicher begriffsgeschichtlicher Theoriebildung liegen dort, wo nicht nur historische Transformationsprozesse beschrieben werden sollen, sondern wo sich auch der historisch konkrete Begriff nicht auf „die ,Klarheit“ des Gegebenen“167 zurückführen lässt, sondern Übertragungen enthält, „die sich nicht ins Eigentliche, in die Logizität zurückholen lassen“. Die „Feststellung und Analyse ihrer begrifflich nicht ablösbaren Aussagefunktion" ${ }^{\text {"168 }}$ gehört nach Hans Blumenbergs Metaphorologie essentiell zur historischen Begriffsarbeit. Auch Heimat kann mit Blumenberg in wichtigen Bereichen ihrer Verwendung als absolute Metapher beschrieben werden, insofern eine Rückübertragung ihres Sinns auf die ursprüngliche Bezugsgröße mit Sinnverlust einhergehen muss. Blumenberg setzt Begriff und Metapher voneinander ab: der Begriff als das eindeutig zu definierende, die Metapher als der sich diesem Definitionsbegehren entziehende Einspruch gegen ein herkömmliches Begriffsverständnis. Heimat lässt sich ausgesprochen leicht metaphorisieren. ${ }^{169}$ Gerade in Bezug auf Heimat kann Begriffsgeschichte daher tatsächlich nicht ohne Metapherngeschichte auskommen, oder anders: Der Begriff soll hier nicht als ein stets klar zu definierender, sondern als sich Eindeutigkeit und Bestimmbarkeit systematisch entziehend verstanden werden.

Die mehrdeutige, ambige oder auch unbestimmt bleibende Semantik von Heimat spielt unter anderem eine herausgehobene Rolle für die Literatur, deren Textwelten durch ihre Unbestimmtheitsstellen, ihr „Opalisieren“, ${ }^{170}$ wie es Roman Ingarden nennt, herausfordern. Gerade der Zustand verschiedener möglicher Bestimmtheiten und die Tendenz zur uneigentlichen Redeweise, die für die Begriffssemantik von Heimat in besonderem Maße gilt, ist attraktiv für die Literatur. Dies ist eine Erklärung, warum die Literatur eine herausgehobene Rolle in der Diskursbildung von Heimat gespielt hat und warum dies gerade um 1800 geschah, also in der Epoche, die Vernunft und Gefühl, Ratio und Kunst in ein neues Verhältnis setzte. Aber Literatur setzt zu diesem Zeitpunkt nur etwas fort, das in der religiösen Sprache schon viel länger eine Rolle spielte, denn die religiöse Semantik von Heimat ist von Anfang an metaphorisch. Erst mit dieser Metaphernbildung wird es ihr möglich, Zeit und Raum zu transzendieren. Auch außerhalb von religiösen Kontexten, wo Heimat vermeintlich für den Ort der Her-

167 Blumenberg 2021, S. 8.

168 Blumenberg 2021, S. 10.

169 Vgl. Mecklenburg 1982, S. 17.

170 Ingarden 1972, S. 269-270. 
kunft steht, schwingt diese alte religiöse Metapher mit - als menschheitsgeschichtlicher Ursprung etwa oder als metaphysische Geborgenheit. Deswegen konnte Heimat als rückwärtsgewandte Utopie bezeichnet werden und konnte Ernst Bloch Heimat als etwas verstehen, „das allen in die Kindheit scheint und worin noch niemand war“. ${ }^{171}$ Auch die Wissenschaften, für die Heimat um 1900 zum Leitbegriff wird - Volkskunde und Pädagogik etwa - verlassen sich auf die durch die Metapher errichtete Aura des Begriffs und haben damit ebenfalls teil an der Herausbildung eines Heimatdiskurses, der gerade auf das Unbegriffliche zielt (vgl. II.3.).

Die Arbeit bewegt sich, wie gezeigt, im Spannungsfeld von drei Forschungsansätzen - der Begriffs-, der Metaphern- und der Diskursgeschichte. Diese Konstellation hat auch Auswirkungen auf die räumlichen und sprachlichen Grenzen der Studie, zu denen hier abschließend Stellung bezogen werden soll. Die Studie umfasst den gesamten deutschsprachigen Raum. Eine engere territoriale Eingrenzung wäre kaum sinnvoll, denn im 19. Jahrhundert war die Nationalstaatsbildung noch nicht abgeschlossen und die Grenzen zwischen den Staaten haben sich teilweise extrem verschoben. Die Untersuchung erweist auch, dass die Ergebnisse im schweizerischen, im österreichischen und im deutschen Raum nicht grundsätzlich voneinander abweichen. ${ }^{172}$ Wie die meisten anderen historischen Studien zu Heimat geht auch diese Studie bis auf einige Seitenblicke nicht über den deutschsprachigen Raum hinaus. Dies hat nicht nur pragmatische Ursachen - etwa die, dass jede andere Entscheidung den Rahmen der Arbeit qualitativ und quantitativ sprengen würde -, sondern lässt sich auch methodisch begründen. Denn eine der zentralen Prämissen der Arbeit, nur das als ,Heimat“ historisch zu rekonstruieren, was auch tatsächlich so genannt wurde, ließe sich nicht aufrechterhalten. Begriffs- und auch metapherngeschichtliche Arbeit ist eng an die Sprache gebunden.

Dabei ist evident, dass komparatistische Fragestellungen in Bezug auf Modelle von Heimat ausgesprochen naheliegend sind. Und insofern sich an den Begriff (je nach Kontext verschiedene) Motive, Ideen, Konzepte und Programme anschließen und er historisch mit unterschiedlichen Praktiken verbunden ist, können natürlich komparatistische Aussagen getroffen werden. Das zeigt in Be-

171 Bloch 1990, S. 1627.

$172 \mathrm{Zu}$ diesem Ergebnis kommt bezogen auf sein Material auch Schumann, dessen Studie ebenfalls dem gesamten deutschsprachigen Raum gilt. Schumann stellt beispielsweise fest, dass Heimat als Begriff in der Regel erst im letzten Jahrhundert in den Titel regionaler Anthologien aufsteigt - in der Schweiz und in Österreich genauso wie in Deutschland -, und leitet daraus ab, dass nicht allein die deutsche Reichsgründung eine Erklärung liefern könne, sondern offenbar zu diesem Zeitpunkt ein übergreifender Konsens hergestellt worden sei. Vgl. Schumann 2002, S. 80. 
zug auf den Regionalismus Norbert Mecklenburg. Er spricht in seiner Studie Erzählte Provinz pointiert von einer ,regionalistischen Internationale ${ }^{\text {1173 }}$ und hat gezeigt, dass der Regionalismus des 19. Jahrhunderts ein gesamteuropäisches und amerikanisches literarisches Phänomen darstellt. Die Anfänge der Dorfgeschichte und des Bauernromans sind nicht nur in Deutschland und der Schweiz, sondern genauso in Frankreich zu finden, George Eliot nobilitiert den englischen Provinzroman als ernstzunehmendes literarisches Genre, Knut Hamsun, Selma Lagerlöf, Lew Tolstoi, Giovanni Verga wurden europaweit als Repräsentanten der skandinavischen, russischen bzw. italienischen Regionalliteratur rezipiert. Europaweit ist die ,erzählte Provinz' als literarische Auseinandersetzung mit der Moderne zu verstehen - in all ihren zivilisationskritischen, antimodernistischen aber auch moderneaffinen Varianten bildet sie das Spannungsverhältnis zwischen Provinz und Moderne literarisch aus. ${ }^{174}$ Damit zusammenhängend und über den literarischen Bereich hinausgehend war beispielsweise auch die Entdeckung der Folklore im letzten Drittel des 19. Jahrhunderts ein Phänomen der westlichen Welt: William John Thoms gründete 1878 die „Folk-Lore Society“ in Großbritannien, Francis James Child 1888 die „American Folklore Society“ in den USA und der Deutsch-Amerikaner Karl Knortz gab 1896 in Dresden das Buch Folklore heraus. Ohne Frage könnte man beispielsweise auch eine globale Literatur- und Philosophiegeschichte entlang des Motivs von Aufbruch, Wanderschaft und Rückkehr ins elterliche Haus schreiben. ${ }^{175}$ Jan Urbichs problemgeschichtliche Studie über Das Subjekt der Heimkehr in Dichtung und Philosophie der Moderne kann in dieser Perspektive Aristoteles, Levinas und Laplanche genauso berücksichtigen wie Hegel, Nietzsche und Hölderlin. ${ }^{176}$

Soll aber nicht nur ein Aspekt von Heimat (wie eben beispielsweise ihre Funktion für Regionalismus und Folklore oder ihr Zusammenhang mit einer Ideengeschichte der Heimkehr) untersucht werden, sondern sollen gerade ihre semantischen Ambiguitäten den Ausgangspunkt und Leitfaden der Untersuchung darstellen, werden diese Vergleichsgrößen immer erst eine sekundäre Rolle

173 Mecklenburg 1982, S. 7.

174 Vgl. Mecklenburg 1982, S. 82-94.

175 Bisher hat sich auch die internationale Forschung allerdings vor allem der Wanderschaft als spezifisch deutscher ,intellectual history‘ gewidmet, vgl. Cusack 2008, zu Aspekten von Heimat S. 191-198. In der hier vorliegenden Studie ist der Aspekt des Wanderns ein durchlaufendes Thema und wird besonders in den Kapiteln zur christlichen Metaphorik des Wanderers (II.1.1) und dem romantischen Wandermotiv (II.1.2), zum Ahasver-Mythos (II.1.3.2), zur Heimatlosigkeit im rechtlichen Sinn (II.2), zu Jahns Deutsches Volksthum (I.2.1), zu Riehls Wanderbuch (II.3.2.1) und zu Fontanes Wanderungen durch die Mark Brandenburg (II.3.2.2) behandelt.

176 Vgl. Urbich 2020. 
spielen können. Die Vieldeutigkeit des Begriffs ist Produkt eines kulturellen Prozesses, der in der Art und Weise, wie er sich in der deutschsprachigen Kultur historisch entwickelte, genauso spezifisch sein muss wie beispielsweise der von homeland für den englischen und amerikanischen Kulturraum. Die Semantik von Heimat überlagert sich offensichtlich in vielen Bedeutungsdimensionen mit patria, tierra natal, homeland, patrie, domov oder ро́дина, sie ist aber keineswegs identisch. Jacob Grimm übersetzt seine lateinische Antrittsvorlesung De desiderio patriae mit ,Über Vaterlandsliebe،, nicht Heimatliebe. ${ }^{177}$ Für diese an einer historischen Semantik arbeitende Studie sind solche Differenzen wichtig, für andere Arbeiten wären sie nebensächlich.

Die Unübersetzbarkeit von Heimat wurde vielfach festgestellt ${ }^{178}$ und ist beispielsweise im Dictionary of Untranslatables dokumentiert, in der auch das deutsche Wort ,Heimat‘ seinen Platz hat. Denn „ohne semantischen Verlust“ lässt sich „das deutsche Wort“ nicht „in andere Sprachen übertragen“. ${ }^{179} \mathrm{Zu}$ dieser kulturgeschichtlich spezifischen Heimatsemantik gehört intrikaterweise auch die

177 Jacob Grimm hielt seine Göttinger Antrittsvorlesung De desiderio patriae (1830) den akademischen Konventionen gemäß auf Latein, kritisiert in ihr aber genau diesen Gebrauch einer Gelehrtensprache. Vaterlandsliebe und nationale ,Blühte‘ könnten sich nur entwickeln, wenn in der eigenen Sprache gesprochen würde (vgl. zu weiteren biographischen Bezügen auch das Kapitel ,Heimatliebe“ in Martus 2009, S. 327-336). Grimm übersetzte Auszüge seines Vortrags selbst ins Deutsche und veröffentlichte sie in den Göttingischen Gelehrten Anzeigen. In dieser zusammenfassenden Übersetzung ist immer wieder von Vaterland und Vaterlandsliebe, von Geburtsland und ein einziges Mal auch von Heimat die Rede: „Nachdem im Eingang derselben [Rede] der Redner die Falschheit des Gemeinspruchs: da wo es dem Menschen wohl ergehe, sey sein Vaterland, gezeigt und gewiesen hatte, wie die Vaterlandsliebe ein so heiliges und jeder menschlichen Brust so tief eingeprägtes Gefühl ist, daß sie durch Leiden und Unglücksfälle, die uns im Geburtslande treffen, nicht geschwächt, sondern eher noch gesteigert wird; schritt er zu der Entwickelung der eigenthümlichen Vortheile, die wir dem väterlichen Boden verdanken. Sie sind von der Art, daß sie durch nichts anderes ersetzt werden mögen und daß den Auswandernden eine oft unbezwingliche Sehnsucht immer wieder nach der Heimath zurück zieht.“ Es sind jeweils andere Aspekte des Bezugs auf den Ort des Herkommens, die mit Vaterland und Heimat benannt werden. Heimat ist hier charakteristischerweise gerade dort eingesetzt, wo die Sehnsucht nach etwas, das verlassen wurde, bezeichnet werden soll. Grimm 1830, S. 2001.

178 Max Frisch hält das Wort in seiner Rede Die Schweiz als Heimat von 1974 für unübersetzbar: „My country erweitert und limitiert Heimat von vornherein auf ein Staatsgebiet. Homeland setzt Kolonien voraus, Motherland tönt zärtlicher als Vaterland, das mit Vorliebe etwas fordert und weniger beschützt als mit Leib und Leben geschützt werden will. La patrie, das hißt sofort die Flagge - und ich kann nicht sagen, daß mir beim Anblick eines Schweizerkreuzes sofort und unter allen Umständen heimatlich zumute wird.“ Frisch 1976, S. 509. Peter Sloterdijk zählt das Wort Heimat „zu einem atmosphärisch geladenen Kernwortschatz“ des Deutschen, „der das unübersetzbare Nationaleigentum der deutschen Sprache ausmacht“. Sloterdijk 1999, S. 24.

179 Piltz 2007, S. 58. 
historisch vielfach vorgetragene Behauptung, dass Heimatgefühl etwas spezifisch Deutsches sei. Dies lässt sich widerlegen: Die Behauptung der Unübersetzbarkeit etwa des Wortes ,Heimweh' ist auch in tschechischen, polnischen oder russischen Texten des 19. Jahrhunderts zu finden und steht damit im Kontext des europaweiten Nationalismus der Zeit. ${ }^{180}$ Susanne Scharnowski diagnostiziert deshalb einen Widerspruch bei jenen, die die „vermeintliche Unübersetzbarkeit“ des Begriffs benutzen, um die „Debatte über Heimat meist ausschließlich um deutsche Geschichte, deutsche Politik, deutsche Gesellschaft und deutsche Kultur“ kreisen zu lassen und so zu einer „strikt nationale[n] Sicht“ gelangen - gerade auch „bei jenen, die den deutschen Nationalismus kritisieren wollen“. ${ }^{181}$ Aus ihrem Ansatz heraus, Heimat als regionales Bezugsangebot auch für unsere Gegenwart zu verstehen, ist es richtig und ergiebig, den Blick auf andere Kulturkreise $\mathrm{zu}$ weiten und solche in diesem Sinn verstandenen Heimat-Modelle auch dort zu suchen (und zu finden). Hier zeigt sich genau der Unterschied des methodischen Ansatzes: Aus der Perspektive des hier gewählten Ansatzes ist Heimat alles, was mit diesem Wort als solche bezeichnet wurde. Die Behauptung, dass Heimatgefühl etwas spezifisch Deutsches sei, wird von dieser Studie daher natürlich nicht zu den Wahrheiten über Heimat gezählt, aber zu den Wahrheiten des deutschsprachigen Heimatdiskurses und damit zu den Aussagen, welche die historische Begriffssemantik bis heute prägen. Diese Studie gilt der historischen Semantik von Heimat und sie wird sie in den eng miteinander zusammenhängenden Bereichen der Literatur, der Religion, des Rechts und der Wissenschaften untersuchen.

180 Vgl. Boym 2001, S. 12-13 und Scharnowski: Heimat, 2019, S. 12. 181 Scharnowski: Heimat, 2019, S. 11. 